\title{
Microalbuminuria In Nondiabetic Acute Ischaemic Stroke
}

\author{
Authors \\ Dr Anand Singh, Dr Poonam Gupta, Dr Anubha Srivastava \\ MLN Medical College \\ Corresponding Author \\ Dr Anand Singh \\ Email: anandsingh2910@gmail.com, Mobile: 8853904950
}

\section{Introduction}

"Cerebrovascular Disease" or "Stroke" is one of the leading causes of mortality and morbidity in adults worldwide, posing serious medical, socioeconomic and rehabilitation problems. Stroke also called 'Brain Attack' because it involves an acute insult to the brain, is a major disabling disease. But throughout the world, unfavourable trends in stroke risk factor profile, lack of prevention programs, lack of awareness of stroke risk factors and warning signals by the public and lack of emphasis on preventive training in medical schools, portend high stroke rates and serve to widen the stroke prevention gap. ${ }^{1}$ This is unfortunate because stroke is well suited for prevention since it has high prevalence, high burden of illness and economic cost, well defined modifiable risk factors and effective prevention measures. $^{2}$

Hence, there is growing interest in unifying mechanisms in ischemic stroke pathogenesis. Overtime, numerous risk factors have been found to be associated with increased occurrence of stroke. But only one half of the cerebrovascular disease risk could be explained by conventional risk factors. The realization that atherosclerosis is an inflammatory disease ${ }^{3}$ has led to a search for new stroke risk factors and treatment.

The markers of inflammation like C-reactive protein, intercellular adhesion molecule-1, lipoprotein associated phospholipase A2, elevated white blood cell count, interleukins, variant endothelial nitric oxide synthase; infectious agents like Chlamydia pneumoniae, Helicobacter pylori and Cytomegalovirus; Homocysteine; Renin angiotensin system; Tissue factor; Fibrinogen; Lipoprotein (a); Small dense LDL; Cytokine transforming growth factor, etc., have been proposed as new risk factors for stroke. ${ }^{4}$ One more addition to the growing list is 'Microalbuminuria'. Microalbuminuria has been associated with many disease entities like diabetic nephropathy, hypertension with left ventricular hypertrophy and renal insufficiency, etc. Microalbuminuria has been associated with clinical risk factors for stroke like diabetes, hypertension, aging, history of myocardial infarction, obesity, smoking and left ventricular hypertrophy. But there was little 
information regarding microalbuminuria as an independent risk factor for stroke or as a predictor of stroke outcome. With the availability of sensitive and relatively inexpensive methods for detection of microalbuminuria, many studies were conducted in different parts of the world to determine the potential use of microalbuminuria, as a marker of stroke risk and outcome in nondiabetic population.

\section{Aims and Objectives}

- To estimate the incidence of microalbuminuria in non-diabetic acute ischemic stroke patients.

- To evaluate the prognostic significance of microalbuminuria in non-diabetic Acute ischemic stroke patients.

\section{Review of Literature \\ Ischaemic Stroke Definition \\ Stroke}

WHO defines stroke as "the rapidly developing clinical symptoms and/or signs of local [at times global] disturbance of cerebral functions, with symptoms lasting for more than 24 hours or leading to death with no apparent cause other than that of vascular origin" [Hatano, 1976]. ${ }^{5}$

\section{Transient Ischaemic Attack (TIA)}

TIA is a clinical syndrome characterized by an acute loss of focal cerebral or monocular function with symptoms lasting less than 24 hours and which is thought to be due to inadequate cerebral or ocular blood supply as a result of arterial thrombosis or embolism associated with arterial, cardiac or hematological disease (Harkey and Warlow, 1994).6 TIA serves as a 'warning signal' for later occurrence of stroke and thus, may form the basis of a 'high risk' prevention strategy.

\section{Reversible Ischaemic Neurological Deficit [RIND]}

RIND defines an event characterized by neurological deficits that lasts more than one day but disappears within 7 days.

\section{Stroke in Evolution}

It describes a progressive neurological deficit developing over a few hours or days, which evolves to completed stroke after a few hours or days.

\section{Completed Stroke}

It is the term applied to the temporal profile of the stroke syndrome in which the deficit is prolonged and often permanent causing demonstrable parenchymal changes.

\section{Small Vessel Stroke}

It is the infarction following atherothrombotic or lipohyalinotic occlusion of a small artery [30 $300 \mathrm{mcm}$ ] in the brain [lacunar infarction].

\section{Classification}

\section{Oxfordshire stroke sub-classification ${ }^{7}$}

\section{A. Total Anterior Circulation Syndrome}

- Implies a large cortical stroke in middle cerebral or middle and anterior cerebral artery territories.

- It is characterized by a combination of:

a) New higher cerebral dysfunction.

b) Homonymous visual field defect.

c) Ipsilateral motor and/or sensory deficit involving at least two out of three areas of the face, arm and leg.

\section{B. Partial Anterior Circulation Syndrome}

- Implies a cortical stroke in middle or anterior cerebral artery territory.

- The patients will have two out of three components of the total anterior circulation syndromes or new higher cerebral dysfunction alone or a motor/sensory deficit more restricted than those classified as total anterior circulation syndromes.

\section{Lacunar Syndrome}

- Implies a subcortical stroke due to small vessel disease.

- Evidence of higher cortical dysfunction or disturbance of consciousness excludes a lacunar syndrome.

\section{Posterior Circulation Syndrome}

- Ipsilateral cranial nerve palsy with contralateral motor and / or sensory deficit.

- Bilateral motor and/or sensory deficit. 
- Disorder of conjugate eye movement.

- Cerebral dysfunction without ipsilateral long tract involvement.

- Isolated homonymous visual field defects.

\section{Hachinske and Norris Classification ${ }^{8}$}

\section{A. Presumed Stroke}

Presumed TIA

\section{B. Anatomic classification:}

a. By vascular supply - Carotid.

\section{Vertebrobasilar.}

b. By location

- Supratentorial - Lobar.

Ganglionic/Thalamic.

- Infratentorial - Cerebellar.

Brainstem.

\section{Etiologic classification:}

a. By result

- Cerebral Infarct - Arterial.

Arteriolar Venous.

- Cerebral hemorrhage - Parenchymal.

Subarachnoid.

b. By cause

- Ischaemia - Embolism.

Extra cranial vascular disease.

- Hemorrhage - Hypertension.

Vascular malformation

Aneurysm.

Amyloid Angiopathy.

\section{Management classification:}

- TIA and minor stroke.

- Major stroke.

- Deteriorating stroke.

- Young stroke.

\section{Epidemiology}

Stroke remains the second leading cause of death worldwide $^{\mathbf{8 8}}$. Stroke is also the leading cause of disability in adults worldwide. Worldwide annual incidence of stroke is $0.2-2.5 / 1000$ population. Worldwide prevalence rate of stroke is 500600/1,00,000 population. ${ }^{\mathbf{1 0}}$

\section{A. Incidence and prevalence of stroke in India}

The first population based study in India regarding incidence of stroke was conducted in Vellore in 2 phases. In the first phase (1968-69), a population of 2,58,576 in and around Vellore was surveyed to detect the prevalent cases of hemiplegia. In the second phase (1969-71), the population was kept under surveillance for two years and attempts were made to record all the incidence cases of hemiplegia. The main observations made during this study are:

1. Two year prevalence rate of stroke -84 per $1,00,000$ population.

2. Annual incidence of stroke - 13 per $1,00,000$ population.

The second study was carried out as a part of WHO collaborative study in Rohtak, Haryana between 1971 and 1974. The study made the following observations:

1. Crude prevalence rate - 44 per $1,00,000$ population.

2. Annual incidence of Stroke - 33 per $1,00,000$ population.

Subsequent study done in Gowribidanur in Karnataka in South India found the prevalence rate of stroke to be 52/1,00,000. In Eastern India, a neuroepidemiological study in rural Bengal found prevalence of stroke to be 126/1,00,000 and in Chottanagapur in Bihar it was 103/100,000. The stroke prevalence in Metropolitan city of Mumbai has been reported as high as $245 / 100,000$. In a smaller study in New Delhi, the crude prevalence of stroke has been reported to be $125 / 100,000$ population.

\section{B. Mortality due to stroke}

WHO estimated that in 1990, out of a total of 9.4 million deaths in India, 6,19,000 deaths were due to stroke, making the stroke mortality rate of 73 per 100,000 .

The estimated number of deaths due to stroke were 22 times than due to Malaria, 1.4 times than due to tuberculosis, 4 times than due to rheumatic heart disease and almost equal to than due to ischemic heart disease. ${ }^{\mathbf{1 1}}$

\section{Risk Factors For Stroke}

1. Age: It is the strongest risk factor for stroke. Stroke is found to be 25 times more 
common in people aged $75-84$ years than in people aged $45-54$ years. 12

2. Sex: There is slight male preponderance in middle and old age. 12

3. Blood Pressure: Increased blood pressure is strongly associated with stroke risk, the risk being present for both systolic and diastolic BP.13,14 The age adjusted relative risk for cerebrovascular disease in hypertension was 3.1 for men and 2.9 for women. 15

4. Smoking: It is a definite risk factor for stroke with a relative risk of about 1.5 . It is established that there is dose-response relationship, affecting both sexes in all age groups. Even passive smoking increases the stroke risk.16

5. Blood lipids: The relationship between blood lipids and stroke is much weaker than that for coronary artery disease, but serum lipoprotein (a) is found to be predictive. 17

6. Diabetes Mellitus: Patients with diabetes have double the risk of stroke compared to non-diabetics.18 Stroke in diabetics is more likely to be fatal.19

7. Haemostatic variables: Increased fibrinogen,20 raised plasma factor VII coagulant activity, low blood fibrinolytic activity, raised von Willebr and factor and raised haematocrit are all risk factors for stroke. 21,22

8. Atrial Fibrillation: AF, especially in patients with the previous embolic event, increasing age, hypertension, diabetes, left ventricular dysfunction, enlarged left atrium etc acts as the most frequent cardiac source of embolism to the brain.23

9. Alcohol: Modest consumption of alcohol might be protective for ischemic stroke. 24 But alcohol also raises the BP,25 alters blood lipids, causes AF and cardiomyopathy and this may increase stroke risk.
10. Obesity: Stroke risk increases particularly if the weight has been gained in middle age or has fluctuated substantially or compounded by hypertension and diabetes. 25

11. Diet: Omega-3 polyunsaturated fatty acids and less saturated fatty acid consumption may reduce stroke risk.27 Excessive salt intake may increase blood pressure and increases stroke risk.28 High intake of potassium reduces the stroke risk by lowering blood pressure. ${ }^{29}$

12. Exercise: It reduces the blood pressure, plasma cholesterol and fibrinogen levels and the risk of NIDDM, thus reducing stroke risk. ${ }^{30}$

13. Non-stroke Vascular Disease: Coronary artery disease, asymptomatic peripheral vascular disease and TIA are all associated with increased stroke risk. ${ }^{31,32}$

14. Genetic Factors: Various vascular anomalies; connective tissue disorders like Ehler-Darlos Syndrome, Pseudoxanthoma elasticum Marfan's syndrome, Fibromuscular hypoplasia, MVP; hematological diseases like sickle cell disease, anti-thrombin III deficiency, protein deficiency, dysfibrinogenemia; familial hypercholesterolaem-ia; cerebral amyloid angiopathy; homocystei-nemia; Fabry's disease; cardiac myxoma; mitochondrial cytopathy etc are associated with increased risk of stroke. ${ }^{33}$ 


\section{Causes of Ischemic Stroke ${ }^{34}$}

\begin{tabular}{|c|c|}
\hline Common causes & Uncommon causes \\
\hline Thrombosis & Hypercoagulable disorders \\
\hline - $\quad$ Lacunar stroke & - $\quad$ Protein $\mathrm{C}$ deficiency \\
\hline Large vessel Thrombosis & Protein S deficiency \\
\hline - $\quad$ Dehydration & Anti-thrombin III deficiency \\
\hline Embolic occlusion & Anti-phospholipid syndrome \\
\hline - $\quad$ Artery-to-artery & Factor V Leiden Mutation \\
\hline Carotid bifurcation & Prothrombin G 20210 Mutation \\
\hline Aortic arch & Systemic malignancy \\
\hline Arterial dissection & Sickle cell anemia \\
\hline - $\quad$ Cardioembolic & $\beta$-Thalassemia \\
\hline Atrial Fibrillation & Polycythaemia vera \\
\hline Mural thrombosis & Systemic lupus erythematosus \\
\hline Myocardial infarction & - $\quad$ Homocysteinemia \\
\hline Dilated cardiomyopathy & - Thrombotic thrombocytopenic purpura \\
\hline Valvular lesions & - Disseminated intravascular coagulation \\
\hline Mitral Stenosis & • $\quad$ Dysproteinemias \\
\hline Mechanical valve & Nephrotic syndrome \\
\hline Bacterial Endocarditis & Inflammatory bowel disease \\
\hline Paradoxical embolus & • $\quad$ Oral contraceptives \\
\hline Atrial Septal defect & Venous sinus thrombosis \\
\hline Patent Foramen ovale & Fibromuscular dysplasia \\
\hline
\end{tabular}

\begin{tabular}{|l|l|}
\hline Common causes & Uncommon causes \\
\hline Atrial septal aneurysm & Vasculitis \\
\hline Spontaneous ECHOContrast & $\begin{array}{l}\text { - Systemic vasculitis (PAN, Wegener's, } \\
\text { Takayasu's, Giant cell arteritis) } \\
\bullet \text { Primary CNS vasculitis } \\
\text { - Meningitis (Syphilis, tuberculosis, fungal, } \\
\text { bacterial, Zoster) }\end{array}$ \\
\hline & Cardiogenic \\
\hline & $\bullet$ Mitral valve calcification \\
\hline & $\bullet$ Atrial myxoma \\
\hline & $\bullet$ Intracardiac tumor \\
\hline & $\bullet$ Marantic endocarditis \\
\hline & Libman-Sacks endocarditis \\
\hline & Subarachnoid hemorrhage vasospasm \\
\hline & Drugs - cocaine, amphetamine \\
\hline & Moyamoya Disease \\
\hline & Eclampsia \\
\hline
\end{tabular}

\section{Diagnostic Approach In Stroke Patients ${ }^{35}$}

- The rapid evaluation of patients is essential for use of time-sensitive treatments such as thrombolysis.

- An adequate history from an observer is essential.

- Once the diagnosis of stroke is made, a brain imaging study is necessary to determine if the cause of stroke is ischemic or hemorrhagic. 


\section{Investigations of TIA and stroke}

\begin{tabular}{|c|c|c|c|c|c|}
\hline \multirow{2}{*}{$\begin{array}{l}\text { Investigation } \\
\text { sequence }\end{array}$} & \multicolumn{4}{|c|}{ Clinical Presentation TIA or Minor stroke } & \multirow[t]{2}{*}{ Reason for investigation } \\
\hline & Lacunar & Hemispheric & Brain Stem & $\begin{array}{l}\text { Severe } \\
\text { Stroke }\end{array}$ & \\
\hline $\begin{array}{l}\text { CT at presentation } \\
\text { (not enhanced) }\end{array}$ & Yes & Yes & Yes & Yes & $\begin{array}{l}\text { To differentiate infarction } \\
\text { from hemorrhage, tumor, } \\
\text { subdural hematoma. }\end{array}$ \\
\hline $\begin{array}{l}\text { U/S scan of carotid } \\
\text { arteries, MRI/MRA } \\
\text { or both }\end{array}$ & No & $\begin{array}{l}\text { Yes if good } \\
\text { recovery }\end{array}$ & No & No & To assess patency of vessels. \\
\hline Echocardiogram & No & $\begin{array}{l}\text { Yes if carotid } \\
\text { MRA normal }\end{array}$ & $\begin{array}{l}\text { Yes if clinical } \\
\text { evidence } \\
\text { cardiac stroke }\end{array}$ & No & $\begin{array}{l}\text { To see for cardiac source of } \\
\text { embolism }\end{array}$ \\
\hline Intra-arterial DSA & No & $\begin{array}{l}\text { Yes, if U/S,MRA } \\
\text { shows significant } \\
\text { stenosis }\end{array}$ & Usually No & No & $\begin{array}{l}\text { More precise evaluation of } \\
\text { intracranial and extracranial } \\
\text { vessels }\end{array}$ \\
\hline $\begin{array}{l}\text { Repeat CT at day 7- } \\
\text { 10or MRA even } \\
\text { earlier }\end{array}$ & Yes if CT & $\begin{array}{l}\text { Yes, if earlier CT } \\
\text { normal }\end{array}$ & $\begin{array}{l}\text { Yes, if earlier CT } \\
\text { normal }\end{array}$ & $\begin{array}{l}\text { Yes, if } \\
\text { earlierCT }\end{array}$ & $\begin{array}{l}\text { For topography of infarct } \\
\text { mechanism and progression }\end{array}$ \\
\hline
\end{tabular}

\section{TREATMENT ${ }^{34}$}

\section{Medical support}

- Protection of airway to avoid obstruction, hypoventilation and aspiration.

- Maintenance of body temperature to prevent hyperthermia.

- Maintenance of blood glucose less than $200 \mathrm{mg} / \mathrm{dl}$ and BP around $150 \mathrm{mmHg}$.

- Maintenance of nutritional status and fluid requirement.
- Watch for brain edema and treat it with mannitol.

- Bowel and bladder care, prevention of pressure sores and infections.

\section{Thrombolysis}

IV rtPA at a dose of $0.9 \mathrm{mg} / \mathrm{kg}$ within 3 hours of stroke onset seems to have a role in the treatment of acute ischaemic stroke.

\section{Administration of intravenous Recombinant Tissue Plasminogen Activator (rtPA) for acute ischemic stroke}

\begin{tabular}{|c|c|}
\hline Indication & Contraindications \\
\hline $\begin{array}{l}\text { - Clinical diagnosis of stroke. } \\
\text { - Onset of symptoms to time of drug administration } \\
<3 \text { hrs. } \\
\text { - CT scan showing no hemorrhage or significant } \\
\text { edema. } \\
\text { - Age }>18 \text { years. } \\
\text { - Consent by patient or surrogate. }\end{array}$ & $\begin{array}{l}\text { - Sustained BP }>185 / 110 \mathrm{~mm} \mathrm{Hg} \text {. } \\
\text { - Platelets }<100,000 ; \mathrm{Hct}<25 \% \text {. Glucose }<50 \text { or }>400 \mathrm{Mg} \% \text {. } \\
\text { - Use of heparin within } 48 \mathrm{hr} \text { and prolonged PTT. } \\
\text { - Rapidly improving symptoms. } \\
\text { - Prior stroke or head injury within } 3 \text { months: prior intracerebral } \\
\text { haemorrhage. } \\
\text { - Major surgery in preceding } 14 \text { days. } \\
\text { - Minor stroke symptoms. } \\
\text { - Gastrointestinal bleeding in preceding } 21 \text { days. } \\
\text { - Recent myocardial infarction. } \\
\text { - Coma or stupor. }\end{array}$ \\
\hline
\end{tabular}

3. Anti-platelet drugs: Use of aspirin within 48 hrs of stroke onset reduced both stroke recurrence and mortality minimally. Agents that act at glycoprotein II b/III receptors are under trial.

4. Anti-coagulation: Trials do not support the use of heparin or other anticoagulants for patients with atherothrombotic stroke. But inspite of absence of evidence, heparin is still used frequently in the treatment of stroke.

5. Neuroprotection: It is the concept of providing a treatment that prolongs the brain's tolerance to ischemia. Hypothermia, excitatory amino acid pathway blockers etc., are under trial. 
6. Rehabilitation: It includes early physical, occupational and speech therapy.

\section{Primary and Secondary Prevention}

- General principles

- Life style modification.

- Evaluation of patients clinical risk profile and control of risk factors like hypertension, hyperlipidemia, diabetes etc.

- Use of alternate day aspirin in high risk patients.

\section{Atherosclerotic Risk factors}

- Use of Angiotensin converting enzyme inhibitors and angiotensin receptor blockers.

- Use of statins.

\section{Anti-platelet drugs}

Aspirin, Clopidogrel and combination of Aspirin and dypridamole are used.

\section{Anti-coagulation therapy:}

Used in embolic stroke to maintain INR 2-3.

\section{Prognostification in Acute Stroke ${ }^{36}$}

The survival, recovery and ultimate outcome of an individual who has sustained in acute stroke may be influenced by many variables:

\section{Demographic variables}

Includes age, gender and race. Survival is found to be significantly better in men than women, young than in old, married than in the single, rural areas than urban areas and in those discharged home than in those transferred to long term care hospitals.

\section{General Medical Characteristics}

Hypertension, diabetes mellitus, heart disease, atrial fibrillation, hyperlipidemia, obesity, past history of stroke, physical inactivity, estrogen therapy, high alcohol consumption and smoking are associated with increased likelihood of recurrent stroke and thereby would influence long term survival. Comorbidities like heart disease, COPD, peripheral vascular disease, Parkinson's disease, polyneuropathy, osteoarthritis etc have a direct effect on functional recovery and compound the patient's disabilities.

\section{Lesion related variables}

Survival is better in infarction than in hemorrhage and in subarachnoid hemorrhage than in intracerebral hemorrhage. Anterior circulation infarcts have higher risk of death and so also intracerebral or subarachnoid hemorrhage. Occurrence of coma at stroke onset reflects severity and is an important predictor of 30-day survival. Bilateral pyramidal signs, generalized seizures, abnormal respiratory pattern etc reflect brain stem dysfunction and in combination are related to a very high risk of early death. Severity of paralysis, urinary and bowel incontinence also adversely influence the outcome.

\section{Specific therapy intervention}

Better management of respiratory and cardiac problems in acute phase may result in decreased mortality.

\section{Biochemical variables}

Hyperglycemia at stroke onset even in nondiabetic patients is an adverse prognostic factor. Protein $\mathrm{C}$ and $\mathrm{S}$ have been found to be decreased in some patients with ischemic stroke and predict adverse outcome. Lipoprotein (a) is found to be an independent risk factor for arteriovascular disease. Recent studies have suggested that presence of microalbuminuria is associated with poor stroke outcome.

\section{Outcome Prediction in Individual Patients ${ }^{34}$}

Several multivariate scoring systems have been developed with the aim of predicting stroke outcome. Important among these are:

1. National Institute of Health Stroke Scale.

2. Canadian Stroke Scale.

3. Scandinavian Stroke Scale.

4. Orpington Prognostic Scale.

5. Fugl-Meyer Assessment.

6. Barthel Index.

7. Communication Index.

Of these, the features of the scoring system used in this study is: 


\section{Scandinavian Stroke Scale ${ }^{37}$}

\begin{tabular}{|c|c|c|c|}
\hline Function & Score & $\begin{array}{l}\text { Prognostic } \\
\text { score }\end{array}$ & $\begin{array}{ll}\text { Long } & \text { term } \\
\text { score }\end{array}$ \\
\hline \multicolumn{4}{|l|}{ Consciousness: } \\
\hline • Fully conscious. & 6 & & \\
\hline - Somnolent can be awaked to full consciousness. & 4 & & \\
\hline - Reacts to verbal command, but not fully conscious. & 2 & & \\
\hline \multicolumn{4}{|l|}{ Eye movement } \\
\hline • No gaze palsy. & 4 & & \\
\hline - Gaze palsy present. & 2 & & \\
\hline - Conjugate eye deviation. & 0 & & \\
\hline \multicolumn{4}{|l|}{ Arm, motor power } \\
\hline - Raises arm with normal strength. & 6 & & \\
\hline - Raises arm with reduced strength. & 5 & & \\
\hline - Raises arm with flexion in elbow. & 4 & & \\
\hline - Can move, but not against gravity. & 2 & & \\
\hline • Paralysis. & 0 & & \\
\hline \multicolumn{4}{|l|}{ Leg, Motor power } \\
\hline - Normal strength. & 6 & & \\
\hline - Raises straight leg with reduced strength. & 5 & & \\
\hline - Raises leg with flexion of knee. & 4 & & \\
\hline - Can move, but not against gravity. & 2 & & \\
\hline • Paralysis. & 0 & & \\
\hline \multicolumn{4}{|l|}{ Orientation } \\
\hline - Correct for time, place and person. & 6 & & \\
\hline - Two of these. & 4 & & \\
\hline - One of these. & 2 & & \\
\hline - Completely disorientated. & 0 & & \\
\hline \multicolumn{4}{|l|}{ Speech } \\
\hline • No aphasia. & 10 & & \\
\hline - Limited vocabulary or incoherent speech. & 6 & & \\
\hline - More than yes / no, but not longer sentences. & 3 & & \\
\hline - Only yes/no or less. & 0 & & \\
\hline \multicolumn{4}{|l|}{ Facial palsy } \\
\hline - None/dubious. & 2 & & \\
\hline - Present. & 0 & & \\
\hline \multicolumn{4}{|l|}{ Gait } \\
\hline - Walks $5 \mathrm{M}$ without aids. & 12 & & \\
\hline - Walks with aids. & 9 & & \\
\hline - Walks with help of another person. & 6 & & \\
\hline - Sits without support. & 3 & & \\
\hline - Bedridden / wheel chair. & 0 & & \\
\hline Maximal Score & & & \\
\hline
\end{tabular}

\section{Microalbuminuria}

\section{Definition}

Microalbuminuria or dipstick negative albuminuria is conventionally defined as urinary albumin excretion between $30-300 \mathrm{mg} / 24$ hour for timed 24 hours urine collections and between 20$200 \mathrm{mg} / \mathrm{L}$ for untimed samples. ${ }^{39}$

\section{Mechanism}

The intimate relationship between low-level albumin excretion and vascular permeability makes urinary albumin excretion highly sensitive to the presence of any inflammatory process including cerebrovascular disease.

The kidney is ideally placed to amplify any small changes in the systemic vascular permeability. The glomeruli receive $25 \%$ of the cardiac output. Of the $70 \mathrm{~kg}$ of albumin that pass through the kidneys every 24 hours, less than $0.01 \%$ reaches the glomerular ultra filtrate (i.e., less than $7 \mathrm{~g} / 24$ hour) and hence enters the renal tubules. Almost all the filtered albumin is absorbed by the proximal tubule via a high affinity, low capacity endocytotic mechanism, with only $10-30 \mathrm{mg} / 24 \mathrm{hr}$ appearing in the urine. Assuming that $7 \mathrm{gm}$ of 
albumin is filtered every 24 hour, $1 \%$ increase in systemic vascular permeability in response to an inflammatory stimulus would result in an additional $70 \mathrm{mg}$ of albumin passing into the filtrate. Since tubular mechanisms for albumin reabsorption are near saturation, urinary albumin excretion would increase from a maximum of 30 to approximately $100 \mathrm{mg} / 24$ hour. ${ }^{40}$

lomerular permeability to albumin is dependent on endothelial charge selectivity as well as size selectivity. The negative charge conferred on the glomerular membrane by its consistent glycoprotein plays a role in restricting the permeability of anionic proteins. Loss of glomerular charge selectivity has been found in both diabetic and non-diabetic population with microalbuminuria. ${ }^{41}$

Other possible mechanisms of microalbuminuria include the following:

1. Systemic transvascular albumin leakage: Transcapillary escape rate of albumin (TERalb) is defined as the fraction of the intravascular mass of albumin (IVMA) going through the vascular bed per unit time. The transcapillary escape rate of albumin is an overall measure of macromolecular permeability of the vascular bed in vivo. As microalbuminuria reflects systemic transvascular leakiness for albumin, which may also allow for a higher degree of lipid insudation into the large vessel wall, this may link microalbuminuria to atherogenesis. $^{42}$

2. Role of sialic acid: Sialic acid has been reported to affect several haematological factors, transvascular permeability and accumulation of lipid in the arterial wall. Studies showed that in subjects without diabetes mellitus, an elevated serum concentration of sialic acid is predictive of atherosclerotic vascular disease in presence of concomitant elevation of urinary albumin excretion. $^{43}$

\section{Impaired arterial dilatory capacity: Slightly} elevated urinary albumin excretion is associated with impaired conduit arterial dilatory capacity in clinically healthy subjects, and this impairment may be explained by a reduced dilatory response to nitric oxide of both endogenous and exogenous origin. Impaired arterial dilatory capacity may contribute to the increased cardiovascular risk in subjects with elevated UAE. ${ }^{49}$

4. Elevated VWF concentrations and other prothrombotic factors: Studies showed that prothrombotic factors like fibrinogen and factor VII C, Von Willebrand Factor antigen (VWF) are elevated in patients with type 1 diabetes complicated by microalbuminuria, so also in hypertensive patients. These were considered a potential markers of endothelial dysfunction. ${ }^{45,46}$

5. Hyperinsulinaemia: In vitro, insulin has been shown to cause smooth muscle cell proliferation; stimulate LDL binding to smooth muscle cells, fibroblasts and monocytes; and stimulate cholesterol synthesis in monocytes. ${ }^{47}$

Hyperinsulinaemia and microalbuminuria are components of metabolic syndrome and are associated with a highly abnormal cardiovascular risk factor pattern.

6. Hyperhomocysteinaemia: The enhanced risk of cardio and cerebrovascular disease with microalbuminuria may also be due in part to an association with hyperhomocysteinaemia, a risk factor for atherosclerosis. ${ }^{48}$

\section{Significance Of Microalbuminuria}

"Microalbuminuria signifies abnormal vascular permeability and its presence may be considered as kidney's notice for markedly enhanced cerebrovascular risk." 49

The importance of microalbuminuria was first appreciated in the early 1980s when two landmark studies in London and Denmark independently reported that it was predictive of development of overt diabetic nephropathy and progressive renal failure..$^{50,51}$

Since then, various studies have established the significance of microalbuminuria in several conditions:

1. Several studies have shown that microalbuminuria in diabetic patients predicts diabetic nephropathy as well as increased cardiovascular and overall mortality. ${ }^{52}$ 
Persistent microalbuminuria in these patients also correlates with the presence of hypertension, obesity and dyslipidemia. ${ }^{53}$ American Diabetes
Association has adopted cut off values for diagnosis of diabetic nephropathy. ${ }^{54}$

\section{ADA guidelines for Diabetic Nephropathy}

\begin{tabular}{|l|l|l|}
\hline Stages & $\begin{array}{l}\text { Albuminuria } \\
\text { cut-off values }\end{array}$ & C \\
\hline Microalbuminuria & $* 20-199 \mathrm{mcg} / \mathrm{min}$. & $\bullet$ \\
\hline & $* 30-200 \mathrm{mcg} / 24$ hours. & $\bullet$ \\
& & T \\
& & \\
\hline & $* 30-299 \mathrm{mg} / \mathrm{gm}$. & \\
\hline & & $\bullet$ \\
\hline & & $\bullet$ \\
\hline Macroalbuminuria & $\geq 200 \mathrm{mcg} / \mathrm{min}$. & $\bullet$ \\
\hline & $\geq 300 \mathrm{mg} / 24 \mathrm{hr}$. & $\bullet$ \\
\hline & $>300 \mathrm{mg} / \mathrm{gm}$. & $\bullet$ \\
\hline & & M \\
\hline & & $\bullet$ \\
\hline
\end{tabular}

1. In 1998 ADA included positive microalbuminuria as risk factor for coronary artery disease in diabetic subjects. ${ }^{55}$

2. Studies have shown that the prevalence of microalbuminuria is enhanced in hypertensive subjects, in particular in those with blood pressure characteristics that are associated with enhanced cardiovascular risk, such as salt sensitivity and an abnormal diurnal blood pressure rhythm. Microalbuminuria possibly identifies at an early stage, hypertensive patients with an enhanced risk of developing the wellknown renal and cardio vascular hypertensive complications. ${ }^{56}$

3. Studies have documented the relationship between the presence of microalbuminuria and other atherosclerotic risk factors such as hypertension, dyslipidaemia and smoking in the general population. Studies have revealed the significance of microalbuminuria as predictor of
Clinical characters

- Abnormal nocturnal fall in BP and rise in BP level.

- Increased

Triglyceride, total and

LDL cholesterol.

- Increased frequency of metabolic syndrome component.

- Endothelial dysfunction.

-Association with diabetic retinopathy, amputation and CVD.

- Hypertension.

- Increased triglycerides, total and LDL cholesterol.

- Asymptomatic

Myocardial ischemia.

- Progressive GFR decline.

increased mortality in elderly
persons.

4. Microalbuminuria is detected early in the course of Acute Myocardial Infarction and is considered as an independent predictor of early mortality in this condition. Microalbuminuria has been found to be proportional to the size of the infarct. Gosling et al suggested that early rise in urinary albumin concentration is useful in distingue-ishing myocardial infarct from Angina. ${ }^{58}$ Spyridon K et al found that microalbuminuria is a strong indepen-dent predictor of 3 year adverse prognosis in patients who has sustain-ned acute myocardial infarction. ${ }^{59}$

5. Roine et al demonstrated that microalbuminuria distinguished bacterial meningitis from aseptic meningitis with specificity of $94 \% .^{50}$

6. Shearman et al found that microalbuminuria peaked 36 hours after admission in patients with acute pancreatitis and that serious complications developed later, only in 
those with the higher values of microalbuminuria. ${ }^{61}$

7. Pallister et al found that microalbuminuria levels 8 hours after admission in trauma victims predicted the development of ARDS with a positive predictive value of $85 \%$ and a negative predictive value of $95 \% .^{62}$

8. Microalbuminuria has been found to be associated with wide variety of inflammatory conditions like rheumatoid arthritis, inflammatory bowel disorder, and surgery etc. ${ }^{63-65}$

9. Highly significant association between microalbuminuria and carotid artery intima-media thickness has been reported - a finding which suggests that microalbuminuria may be a marker for early development of carotid artery atherosclerosis and points to a possible linkage between microalbuminuria and atherothrombotic stroke mechanism. ${ }^{66}$

\section{Studies Relating Microalbuminuria And Ischaemic Stroke}

Although microalbuminuria is associated with clinical risk factors for stroke including diabetes, hypertension, aging, history of myocardial infarction and left ventricular hypertrophy there was little information regarding microalbuminuria being independent risk factor for stroke or as predictor of stroke outcome. But in recent times, several studies have been conducted to ascertain any relationship between microalbuminuria and ischaemic stroke.

1. Damsgaard EM et al followed 216 people who had been selected as control subjects for diabetics during a systematic screening for diabetes mellitus among all people aged between 60-74 years, living in municipality of Fredericia, Denmark, between Feb 1981 and Dec 1987. Extensive clinical and biochemical examination found median urinary albumin excretion rate of $7.52 \mathrm{mcg} /$ min. 8 of those with a rate below the median died compared to 23 with a rate equal to or greater than the median. The median albumin excretion rate in the 31 who died was 15 $\mathrm{mcg} / \mathrm{min}$ and cardiovascular disease was the main cause of death in both groups. ${ }^{67}$

2. Yudkin et al used Islington Diabetes Survey in 1988 to study urinary albumin excretion and found that urinary albumin excretion had skewed distribution with maximum rate of $191.9 \mathrm{mcg} / \mathrm{min}$. There was significant correlation between albumin excretion rate and systolic $\mathrm{BP}$, diastolic $\mathrm{BP}$ and 2 hour blood glucose, but not with age, sex or body mass index.68

3. Heikke Miettinen et al followed up cohorts of non-diabetics [ $\mathrm{n}=1375]$ and NIDDM [ $\mathrm{n}=1056]$ subjects in Finland between 1982 and 1990 and found elevated urinary albumin excretion in $25 \%$ non-diabetics and $58 \%$ of NIDDM patients. All case mortality was higher both in non-diabetic and NIDDM subjects with borderline or clinical proteinuria, than in those without proteinuria. ${ }^{69}$

4. Mlacak B et al studied the frequency of albuminuria in patients with and without diabetes (138/160) randomly selected from a stratified sample comparable with known diabetes by age, sex and profession in Metlika country, Slovenia between 1994 to 1998. The groups were examined in the same way and mortality was followed over 5 years. Albuminuria was significantly high in diabetics, peripheral arterial disease, hypertension, coronary heart disease and hyperlipidemia. The albuminuria 
was frequent in those who died in the observed 5 year period. $^{70}$

5. Nancy B. Beamer et al conducted a study in Portland Veterans Administration and Oregon Health Sciences University Hospital in Portland around 1999 and found that microalbuminuria was 3 times more prevalent in patients with recent stroke (29\%) than in those with clinical risk factors for stroke (10\%) and was undetectable in healthy elderly controls. During follow up period of $1.5 \pm 0.9$ years, $20 \%$ of patients with recent stroke, $14 \%$ with risk factors for stroke and $0 \%$ of healthy elderly volunteers had vascular end points with events being as frequent in patients with microalbuminuria (32\%) as in patients with macroalbuminuria $(33 \%) .^{71}$

6. Yuyun MF et al conducted a population based prospective cohort study in British population consisting of 23,630 individuals between 40-79 years, and followed them up for 7 years (1993 - 1997), with baseline albuminuria tested. A total of 246 stroke events occurred. Age adjusted incidence of stroke increased significantly across categories of baseline albuminuria. They concluded that microalbuminuria is independently associated with approximately 50\% increased risk of stroke in the general population. $^{72}$

7. Hans. L. Hillege et al conducted PREVEND (Prevention of Renal and Vascular End Stage Disease) study in Groningen, Netherlands around 2001 and found that increased level of albuminuria was more frequent with advanced age, male sex, diabetes, hypertension, hyperlipidemia, smoking etc. Although micro and macroalbum- inuria was found more frequently in diabetic and hypertensive sub group, microalbuminuria was still prevalent in $6(6 \%)$ of the non-diabetic, non-hypertensive subjects and independently associated with cardiovascular risk factors and morbidity. ${ }^{73}$

8. Turaj $\mathrm{W}$ et al conducted a study on 52 patients in stroke unit of Neurological Department in Jagiellonian University, Caracow, Poland within 24 hours after stroke onset (2001). Microalbuminuria was found in 24 of 52 stroke patients $(46.1 \%)$ and in 5 of 37 controls $(13.5 \%) \quad(\mathrm{p}<0.05)$. The 90 day mortality was higher in patients with microalbuminuria as compared to patients without microalbuminuria (45.8\% Vs. $7.1 \%)$. Patients with microalbuminuria scored lower on the Scandinavian stroke scale than patients without microalbuminuria, both on admission and later. ${ }^{74,83}$

9. Słowik $\mathrm{A}$ et al studied patients admitted within $24 \mathrm{~h}$ of their first ischemic stroke, 50 patients with a history of ischemic stroke, and 30 control subjects without known cerebrovascular diseases in 2002. Neurological deficit was assessed by the Scandinavian Stroke Scale (SSS) on admission and on days 1, 7, 14, and 30. Urinary albumin excretion was measured, with 24-hour collections performed on day 2. Outcome was assessed by 30-day, 90-day and 1-year mortality. Microalbuminuria was found in $46.7 \%$ of patients with acute stroke, $16 \%$ of subjects with a history of stroke, and $16.7 \%$ of controls. On admission, acute stroke patients with microalbuminuria had more severe neurological deficit (median of SSS score on admission was 28 vs. 40, and on day 1,22 vs. 39 , both $\mathrm{p}<0.05$ ) and 
more often had a decreased level of consciousness (32 vs. 10\%, p < 0.05). Mortality was higher in the group of patients with microalbuminuria in acute stroke ( 21 vs. $3 \%$ after 30 days, 39 vs. $6 \%$ after 90 days and 50 vs. $9 \%$ after 1 year, $\mathrm{p}<0.05)$. In logistic regression analysis, microalbuminuria was found to be an independent predictor of 1-year mortality after ischemic stroke ${ }^{82}$.

10. Mathur P.C. et al studied 50 patients of nondiabetic acute ischaemic stroke within 24 hours of onset of symptoms for MA by dipstick urinalysis in 2005 in India .The incidence of MA was $68 \%$ (34 patients). Of all the traditional risk factors for stroke- age, male gender, hypertension, dyslipidaemia, smoking, obesity - only age of patients (>60 years) showed a positive correlation with the presence of MA $(<0.05)$. Patients with MA had more severe neurological deficit (Scandinavian Stroke Scale $\{$ SSS $\}<$ 30 vs. $>30$; mean+S.D=24.3+8.66 vs. $30.3+10.3, \mathrm{p}<0.03$ ) and more severe depressed levels of consciousness $\{\mathrm{SSS}<4$ vs. $\mathrm{SSS}>6,82.35$ vs. 17.6, $\mathrm{p}<0.05)$. The incidence of $\mathrm{MA}$ in Indians with nondiabetic acute ischaemic stroke is significantly higher than that of western populations. Patients with MA in the first 24 hours after the onset of stroke have more severe neurological deficit and depressed levels of consciousness than patients without $\mathrm{MA}^{84}$.

11. Lima H.N et al evaluated and followed for at least 7 months patients with firstever stroke or transient ischemic attack admitted to a prospective cohort from March 2005 to December 2007. analyzed traditional $\mathrm{CV}$ risk factors, albumin-to-creatinine ratio and eGFR $(\mathrm{ml} / \mathrm{min} / 1.73 \mathrm{~m} 2)$ as predictors of mortality or recurrence.From a total of 185 patients included, 38 patients suffered from a recurrent stroke or died, with a mean follow-up of $25.1 \pm$ 8.7 months. AUr ( $\geqq 30 \mathrm{mg} / \mathrm{g})$ was found in $50.2 \%$ (93/185), and $38.9 \%$ (72/185) presented an eGFR <60. In univariate analysis, age $>65$ years, eGFR $\leq 50$, atrial fibrillation (AF), no alcohol intake and $\mathrm{AUr}>17 \mathrm{mg} / \mathrm{g}$ were associated with the composite endpoint. In a multivariate analysis, $\mathrm{AF}$ and $\mathrm{AUr}>17 \mathrm{mg} / \mathrm{g}$ were independent predictors of the composite endpoints, but eGFR $\leq 50$ was not. The presence of AUr $>17$ $\mathrm{mg} / \mathrm{g}$ is independently associated with death or recurrence after stroke ${ }^{85}$.

12. Yoko Watanabe et al divided into 3 groups 166 consecutive patients with acute ischemic stroke who were admitted to their Stroke Center in $2011,1)$ those with proteinuria $(n=47)$, 2) those with microalbuminuria alone $(n=43)$, and 3) those without microalbuminuria or proteinuria $(n=76)$. analyzed the relationship of each group to the subtype of ischemic stroke, the National Institutes of Health Stroke Scale scores (NIHSS) on admission and at discharge, risk factors for ischemic stroke (hypertension, diabetic mellitus, dyslipidemia, previous stroke, and smoking), plasma levels of high-sensitivity C-reactive protein (hs- CRP), and cerebral white matter lesions (periventricular hyperintensity; PVH, and deep white matter hyperintensity; DWMH) on brain magnetic resonance imaging (MRI).Patients with proteinuria or microalbuminuria had higher NIHSS scores on admission and at discharge than patients without proteinuria or 
microalbuminuria. In groups with proteinuria or microalbuminuria, the incidence of cerebral white matter lesions was high ${ }^{86}$.

13. Gumbinger $\mathrm{C}$ et al included Patients with acute ischemic stroke admitted to stroke unit in this study. Clinical history and vascular risk factors were recorded. Severity of stroke and outcome were assessed by NIHSS and modified Rankin scale (mRS) upon admission and discharge. Urinary albumin excretion was measured in 24$\mathrm{h}$ urine samples. multivariate analysis was performed to investigate predictors of poor outcome. MA was found in $43 \%$ of 138 patients and was associated with elevated levels of Creactive protein (CRP), glucose at baseline, and $\mathrm{HbA1c}$; higher rates of diabetes mellitus and atrial fibrillation; higher systolic blood pressure; greater age; and higher premorbid mRS, NIHSS upon admission/discharge, and mRS upon discharge. In a multivariate analysis, MA, premorbid mRS, and NIHSS upon admission were independent predictors of poor outcome upon discharge. MA was frequently found in acute ischemic stroke patients. It was associated with severe neurological deficit upon admission and severe functional impairment upon discharge. MA in the acute phase was shown to be an independent predictor of poor outcome ${ }^{87}$.

\section{Tests for Microalbuminuria}

In 1963, Keen and Chlouveraskis described the first specific radioimmunoassay (RIA) for albumin in urine.75 Since then several methods have been described for measurement of urinary albumin excretion with emphasis on unexpensive, easy to apply, rapid tests which can be used on a large scale population. The various methods used are:

\section{Dipstick method}

Semi quantitative method.

- Chemical precipitation (Sulphosalicyclic acid trichloroacetic acid)

- Immuno precipitation (Micral Test).

3. Photometric method.

4. Nephelometric method.

5. Sensitive Quantitative methods

- Radio immunoassay.

- Cellulose acetate, agarose gel electrophoresis.

The procedures of various important methods include the following:

1. Dipstick method: Chemically impregnated dipstick contains methyl red and bromophenol blue with buffering salts. The later dissolve on contact with urine and protein in the urine lowers the $\mathrm{pH}$ turning it green. It was traditionally known to detect albuminuria $>300 \mathrm{mg} / \mathrm{L}$ and hence not advocated for screening for microalbuminuria. But in a study by Alfredo Pegoraro et al, they found that the combination of sulfosalicylic acid testing and chemstrips was as good as and less expensive than Micral-Test in ruling out microalbuminuria. ${ }^{76}$

2. Chemical precipitation (Sulphosalicylic acid test): 5 drops of $20 \%$ Sulphosalicylic acid is added to $3 \mathrm{ml}$ of urine in one test tube. This test tube is compared with test tube of untreated urine held against a dark background, immediately and turbidity is taken to indicate proteinuria. 77

3. Immunoprecipitation (Micral test): It is based on color shift of monoclonal antibody to human albumin labelled with gold. Here Gold Labelled Optically Read Immuno Assay detects microalbuminuria. A specimen of the urine sample passes via the wick fleece into the conjugate fleece. Any albumin present in the urine binds itself specifically to the gold labelled antibodies. Excess antibodies are bound by immobilized albumin in the capture matrix. Only antibodies bound to albumin from the urine sample can pass through the capture matrix. 
These gold-labelled antibodies flow to the detection pad and turn it red. Test is performed on early morning random urine sample by immersing the strip for $5 \mathrm{sec}$ and reading the result at $2 \mathrm{~min}$, visually comparing with color blocks on vial (0 $\mathrm{mg} / \mathrm{l}, 20 \mathrm{mg} / \mathrm{l}, 50 \mathrm{mg} / \mathrm{l}$ and $100 \mathrm{mg} / \mathrm{l}$ albumin).77

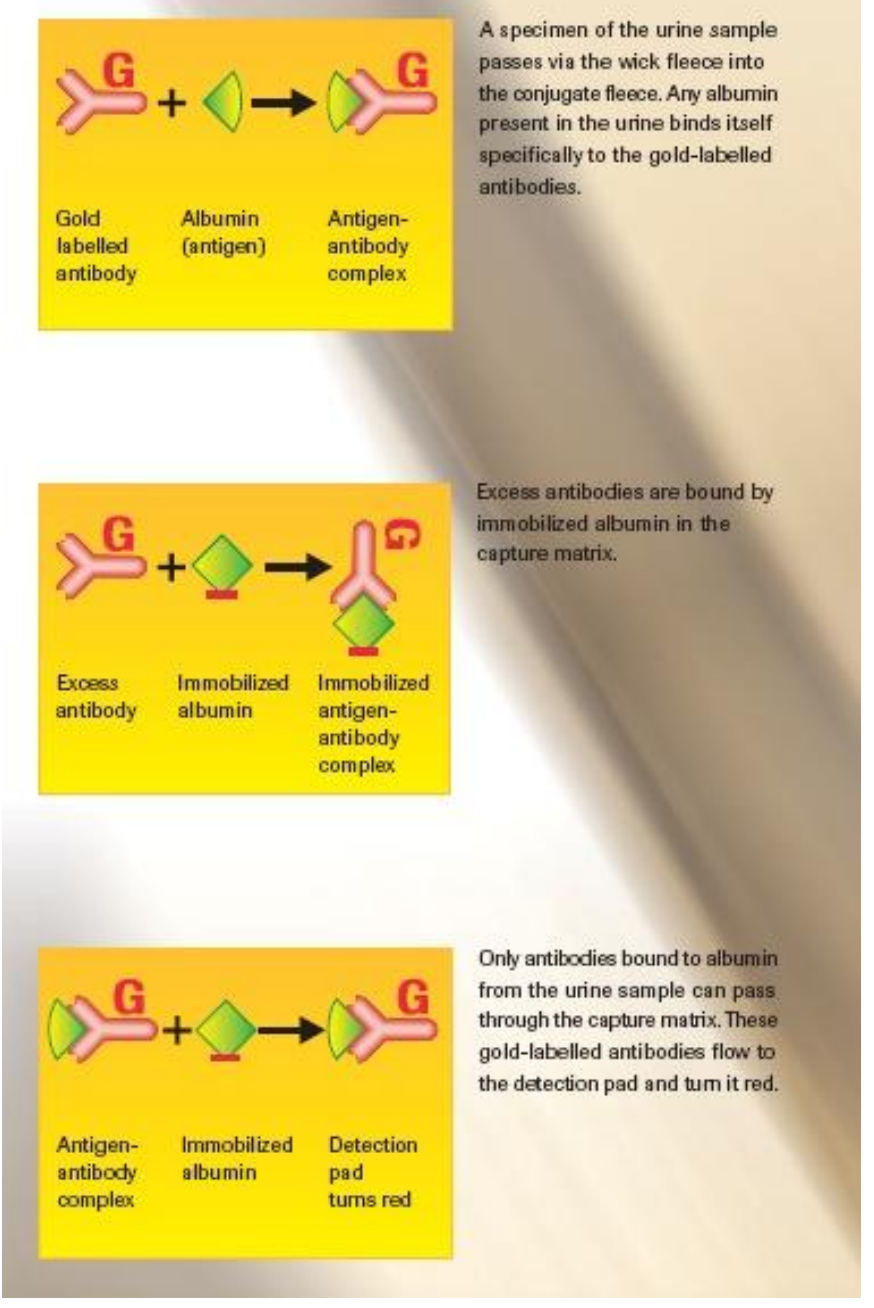

\section{Principle of Micral Test}

4. Radioimmuno assay: It is the "gold standard" for estimation of albuminuria. It is a double antibody technique where albumin in the sample has to compete with the fixed amount of $125 \mathrm{I}$. Labelled albumin for the binding sites of the specific antibodies. Bound and free albumin is separated by addition of a second antibody immuno absorbent followed by centrifugation and decanting. The radio activity in the pellet is measured with a C-counter, Albumin concentration in the sample is inversely proportional to the radioactivity. The sensitivity for RIA method was $0.3 \mathrm{mg} / \mathrm{l}$.
An algorithm for screening of microalbuminuria

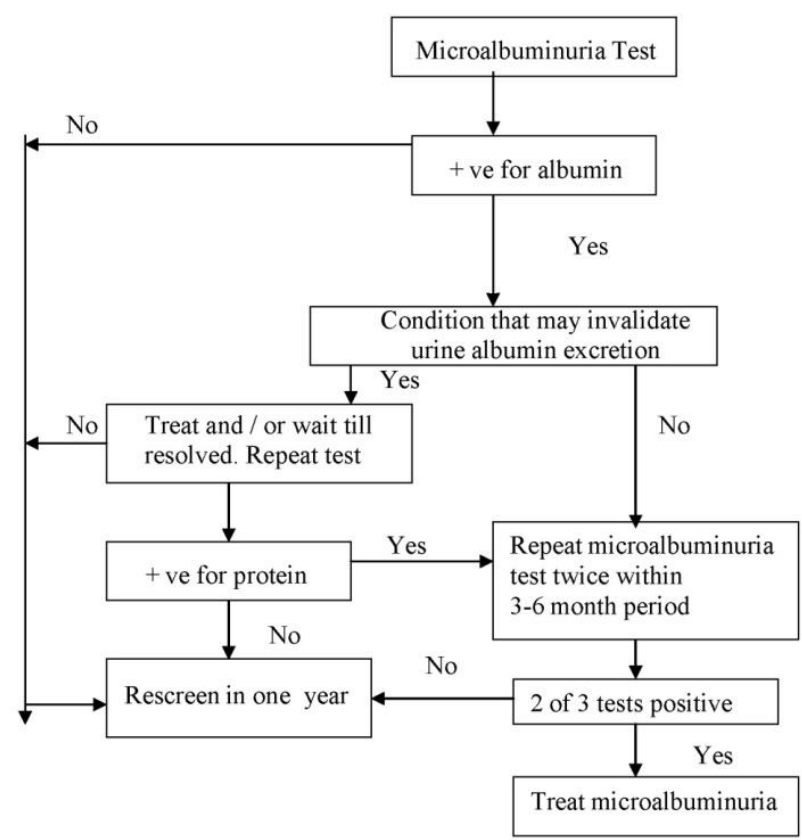

\section{Treatment of Microalbuminuria}

1. Control of Blood pressure: Systolic BP is one of the most relevant determinants of microalbuminuria. Studies of secondary prevention have shown that blood pressure reduction effectively reduces the albumin excretion rate. Among anti- hypertensives, ACE inhibitors and Angiotensin receptor blockers seem to be particularly effective.78 The target BP should be $<140 / 90 \mathrm{mmHg}$ in non-diabetics and < $130 / 80 \mathrm{mmHg}$ in diabetic patients.

2. Glycemic control: Intensive diabetic therapy can significantly reduce the risk of development of microalbuminuria and overt nephropathy in people with diabetes.79

3. Treatment of Dyslipidaemia: Statins modify endothelial dysfunction, inflammatory response, plaque vulnerability and thrombus formation. Their usage is known to slow progression of microalbuminuria and is associated with stabilization of UAE. 80

4. Smoking cessation: Smoking should be strongly discouraged in patients with microalbuminuria not only to retard the progression of microalbuminuria but also to guard against cardiovascular disease. 
5. Protein restriction: Animal studies have shown that restriction of dietary proteins intake reduces hyper filtration and intraglomerular pressure hence retarding the progression of microalbuminuria. The general consensus is to prescribe a protein intake of $0.8 \mathrm{~g} / \mathrm{mg} / \mathrm{day}$ in patients with overt nephropathy.

\section{Microalbuminuria: A Practical Perspective}

Several pathways may link microalbuminuria and vascular disease. Several factors that cluster with microalbuminuria include insulin resistance, central obesity, low levels of high-density lipoprotein, cholesterol, high triglyceride levels, systolic hypertension, lack of nocturnal dip in blood pressure on 24 hour monitoring, salt sensitivity, endothelial dysfunction, hypercoagulability, impaired fibrinolysis and renal dysfunction. This provides enough proof to support the role of microalbuminuria as a predictor or vascular events in high-risk population. Hence, screening for microalbuminuria on a regular basis may help to identify a subgroup of patients who are at high risk for cerebrovascular disease and need more intensive therapy and closer follow-up because they could benefit from early intervention and treatment. 81

\section{Materials and Methods}

\section{Source of data}

- The proposed study is conducted in the Department of Medicine, S.R.N. Hospital, Allahabad.

\section{Inclusion criteria}

- It include patients diagnosed with ischemic stroke irrespective of age and sex confirmed by CT scan brain, within 24 hours after the onset of symptoms.

- The severity of neurological deficit will be measured by the Scandinavian Stroke Scale (SSS).
The albumin excretion rate will be measured using spot urine collection by Micral Test.

\section{Exclusion criteria}

a) Patients with hemorrhagic stroke.

b) Patients with diabetes, defined as fasting plasma glucose $>126 \mathrm{mg} / \mathrm{dl}$ or 2-hour plasma glucose $>200 \mathrm{mg} / \mathrm{dl}$ during an oral glucose tolerance test or use of antidiabetic drugs.

c) Patients with hypertension, defined as systolic blood pressure $>140 \mathrm{mmHg}$ or diastolic blood pressure $>90 \mathrm{mmHg}$ or the use of anti-hypertensive medication.

d) Systemic infection including bacterial meningitis.

e) Nephropathy and abnormal urinalysis.

f) Major trauma and surgery.

- Detailed history, clinical examination and relevant laboratory investigation were done as per the proforma.

- The severity of stroke was assessed using Scandinavian Stroke Scale.

In the selected patients, the following investigations were done.

1. CT scan brain (plain) to establish the ischemic lesion.

2. Urinalysis, to exclude hematuria, leucocyturia, glucosuria and proteinuria.

3. Serum glucose levels, blood urea, serum creatinine and fasting lipid profile were estimated.

4. ECG, chest x-ray and echocardiogram were done to assess the cardiac status.

5. The albumin excretion rate was assessed using Micral test on early morning urine sample and expressed as --------- mg/L.

- 60 age and sex matched healthy controls were selected.

- The controls were screened for stroke risk factors and assessed for urinary albumin excretion rate using Micral test, 
urea,creatinine, serum glucose, WBC count, total cholesterol, LDL, HDL and triglycerides.

\section{Method of Statistical Analysis}

The data was collected and entered in Microsoft excel. The graphs and tables were generated using Microsoft Word and Excel. The analysis of the data was done using the statistical Software namely SPSS 11.0 and Systat 8.0. Chi-square and Fisher Exact Test were used to test the significance of proportions of predisposing Factors and presence of microalbuminuria between cases and controls. Similar tests were used to find the significance of proportion of presenting factors and age between the microalbuminuria positive and negative patients. Student $t$ test (Two tailed) was used to test the significance of mean pattern of parameters between cases and controls and microalbuminuria positivity and negativity.

1. Chi. Square Test

$\mathrm{X} 2=\Sigma(\mathrm{Oi}-\mathrm{Ei}) 2$ where $\mathrm{Oi}$ is observed frequency and $\mathrm{Ei}$ is expected

Ei frequency.

2. Fisher Exact Test

\begin{tabular}{|l|c|c|c|}
\hline & Class 1 & Class 2 & \\
\hline Sample 1 & A & B & $\mathrm{a}+\mathrm{b}$ \\
\hline Sample 2 & C & D & $\mathrm{c}+\mathrm{d}$ \\
\hline Total & $\mathrm{a}+\mathrm{c}$ & $\mathrm{b}+\mathrm{d}$ & $\mathrm{A}$ \\
\hline
\end{tabular}

Fisher Exact Test statistic $=\Sigma P=1$

\section{Student $\mathbf{t}$ test (Independent)}

Objective: To investigate the significance between the means of two populations

$$
\begin{array}{cl}
\mathrm{t}= & (\mathrm{x} 1-\mathrm{x} 2)-(\mu 1-\mu 2) \\
\sqrt{ } \mathrm{s}^{2}(1 / \mathrm{n} 1+1 / \mathrm{n} 2) & \mathrm{n} 1 \\
\text { Where }^{2}= & \mathrm{n}^{2} \\
\mathrm{i} 1-1) \Sigma(\mathrm{x} 1-\mathrm{x} 1)^{2}+(\mathrm{n} 2-1) & \sum^{\mathrm{i}-1} \quad(\mathrm{x} 2-\mathrm{x} 2)^{2} \\
\mathrm{n} 1+\mathrm{n} 2-2 &
\end{array}
$$




\section{Observations}

Study Design: This comparative study consisting of 60 non-diabetic acute ischemic stroke patients as cases and 60 healthy individuals as controls had the following findings.

\section{Table-1: Age distribution}

\begin{tabular}{|l|c|c|c|c|}
\hline \multirow{2}{*}{ Age in years } & \multicolumn{2}{|c|}{ Cases } & \multicolumn{2}{c|}{ Controls } \\
\cline { 2 - 5 } & Number & \% & Number & \% \\
\hline$\leq 20$ & - & - & - & - \\
\hline $21-30$ & 2 & 3.33 & 1 & 1.67 \\
\hline $31-40$ & 3 & 5.00 & 4 & 6.67 \\
\hline $41-50$ & 5 & 8.33 & 9 & 15.00 \\
\hline $51-60$ & 19 & 31.67 & 17 & 28.33 \\
\hline $61-70$ & 21 & 35.00 & 15 & 25.00 \\
\hline$>70$ & 10 & 16.67 & 14 & 23.33 \\
\hline Total & 60 & 100.00 & 60 & 100.00 \\
\hline Mean \pm SD & \multicolumn{3}{|c|}{$60.77 \pm 13.02$} & \multicolumn{3}{|l}{$59.88 \pm 13.10$} \\
\hline Inference & \multicolumn{4}{|l}{ Two samples are age matched with $\mathrm{p}=0.7096$} \\
\hline
\end{tabular}

Figure-1: Age distribution

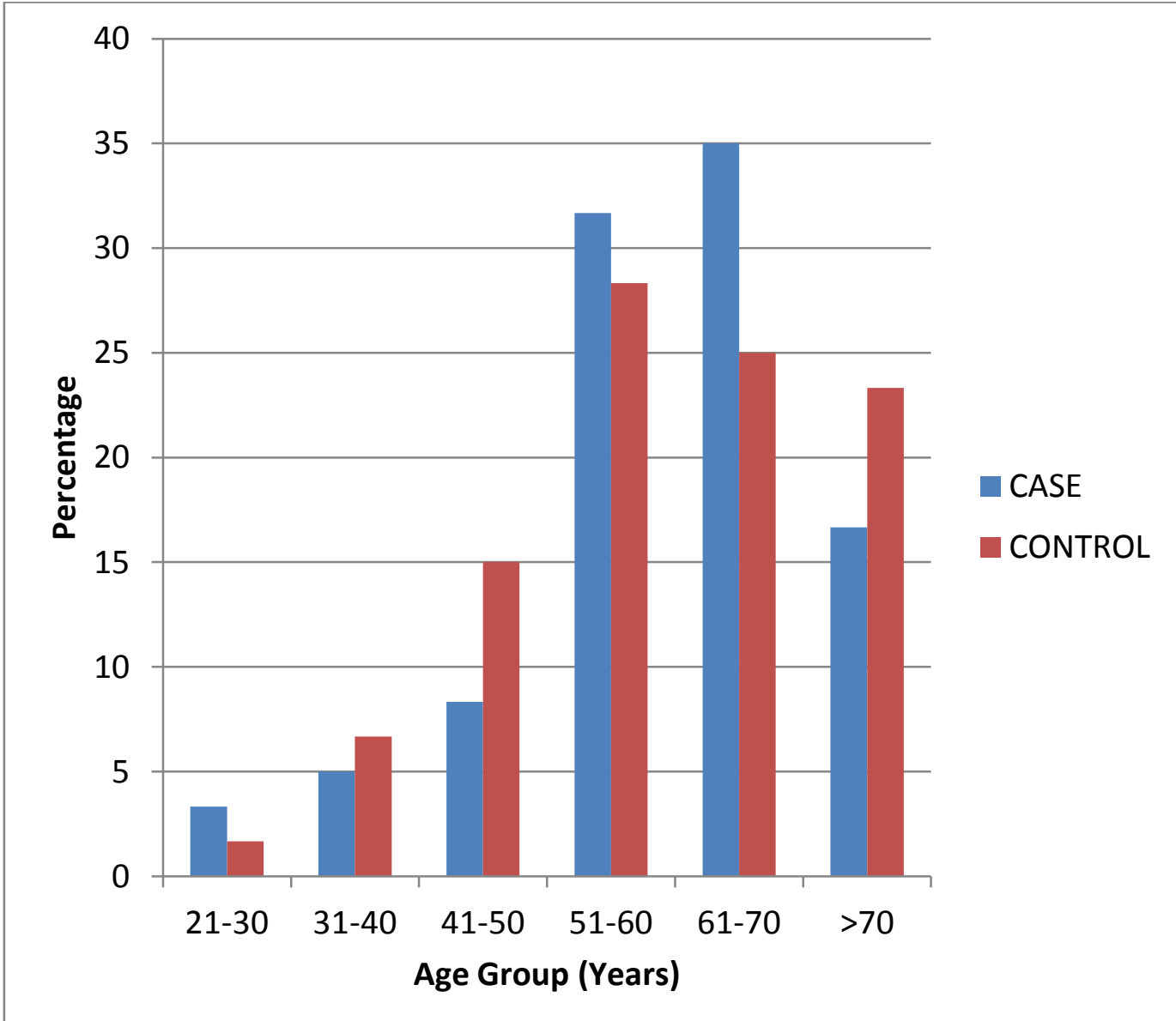

Among the cases, the youngest patient was 22 years old and the oldest patient 90 years. The mean age was $60.77 \pm 13.02$ years.

Among the controls, the youngest patient was 26 years and oldest patient was 85 years. The mean age was $59.88 \pm 13.10$ years.
Hence the cases and controls were age matched with $\mathrm{p}=0.7096$ 


\section{JMSCR Vol||05||Issue||01||Page 15680-15715||January}

Table-2: Sex distribution

\begin{tabular}{|l|c|c|c|c|}
\hline \multirow{2}{*}{ Age in years } & \multicolumn{2}{|c|}{$\begin{array}{c}\text { Cases } \\
(\mathbf{n = 6 0})\end{array}$} & \multicolumn{2}{c|}{$\begin{array}{c}\text { Controls } \\
(\mathbf{n = 6 0})\end{array}$} \\
\cline { 2 - 5 } & Number & \% & Number & \% \\
\hline Male & 47 & 78.33 & 44 & 73.33 \\
\hline Female & 13 & 21.67 & 16 & 26.67 \\
\hline
\end{tabular}

Figure-2 : Sex distribution
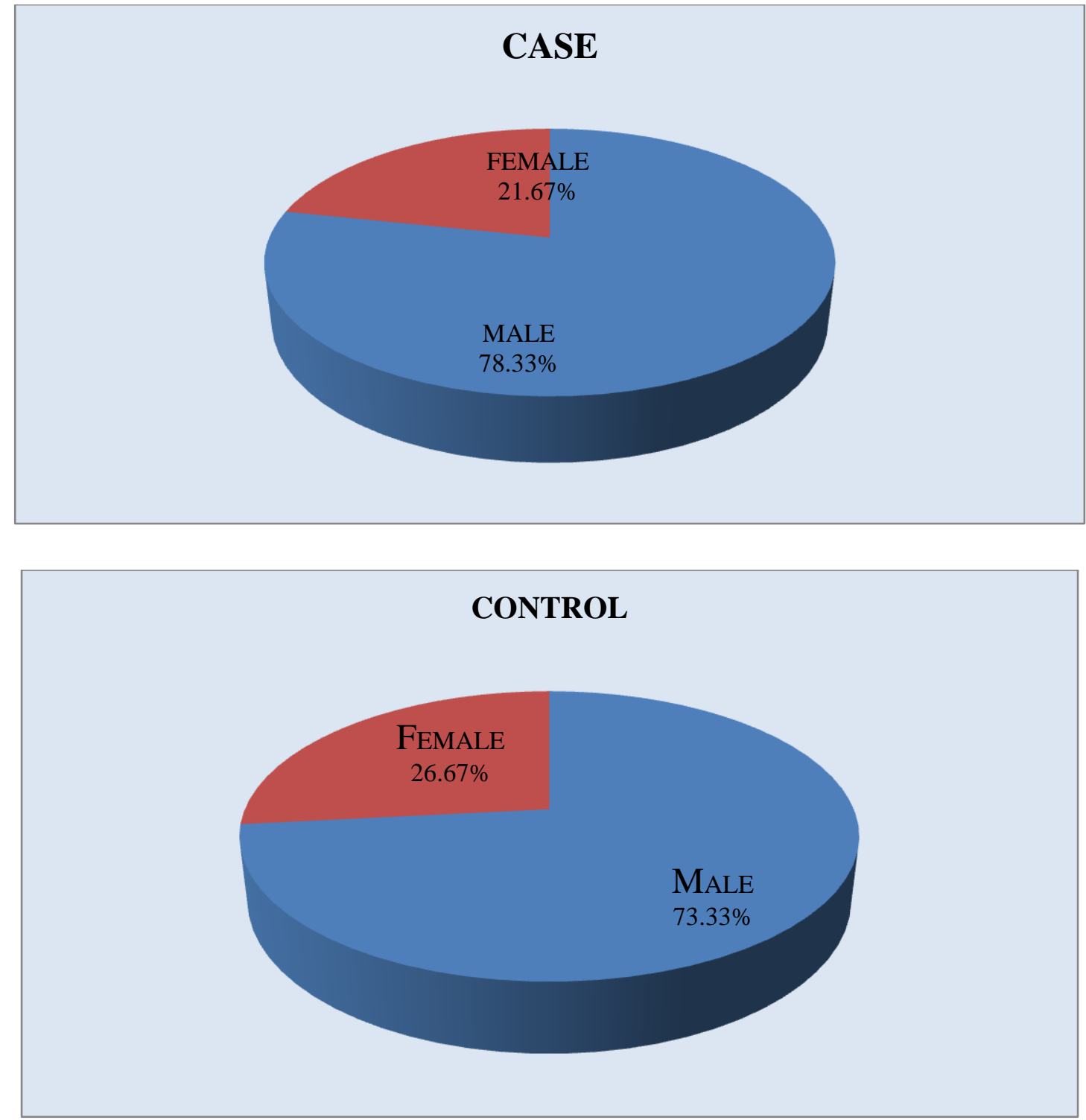

Table -3: Predisposing factors

\begin{tabular}{|l|c|c|c|}
\hline Predisposing factors & Cases(n=60) & Control(n=60) & P value \\
\hline smoking & $30(50.0 \%)$ & $26(43.3 \%)$ & 0.599 \\
\hline alcohol & $21(35.0 \%)$ & $24(40.0 \%)$ & 0.647 \\
\hline History of previous vascular events (h/o PVE) & $9(15.0 \%)$ & $6(10.0 \%)$ & 0.709 \\
\hline inference & $\begin{array}{l}\text { The predisposing factors are statistically similar } \\
\text { between two groups (p>0.05) }\end{array}$ \\
\hline
\end{tabular}


Figure-3 : Predisposing factors

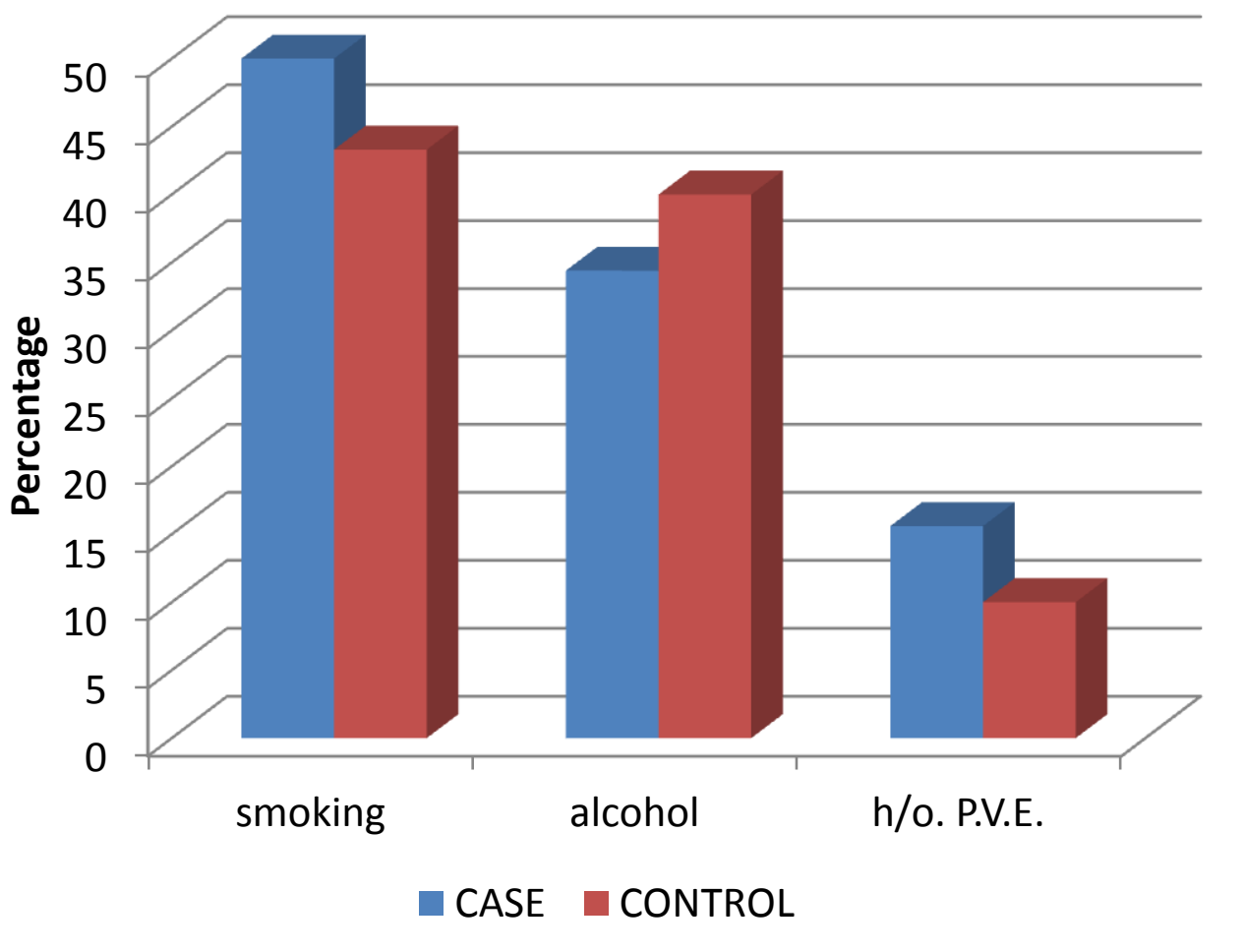

In the study population, the predisposing factors included smoking being $30(50 \%)$ in cases and 26 $(43.3 \%)$ in controls and alcoholism being 21 $(35.0 \%)$ in cases and $24(40 \%)$ in controls.
The history of previous vascular events including ischemic heart disease and peripheral vascular disease was found in $9(15.0 \%)$ of cases and $6(10.0 \%)$ of controls. The predisposing factors were thus statistically similar between two groups.

Table - 4: Incidence of microalbuminuria among study population

\begin{tabular}{|l|c|c|}
\hline Microalbuminuria & Cases (n=60) & Controls (n=60) \\
\hline Absent & $19(31.67 \%)$ & $52(86.67 \%)$ \\
\hline Present & $41(68.33 \%)$ & $8(13.33 \%)$ \\
\hline Inference & \multicolumn{2}{|c|}{$\begin{array}{l}\text { Patients with acute ischemic stroke are 5.125 times more likely to } \\
\text { have microalbuminuria with P = o.ooo1 }\end{array}$} \\
\hline
\end{tabular}

Figure -4: Incidence of microalbuminuria among study population

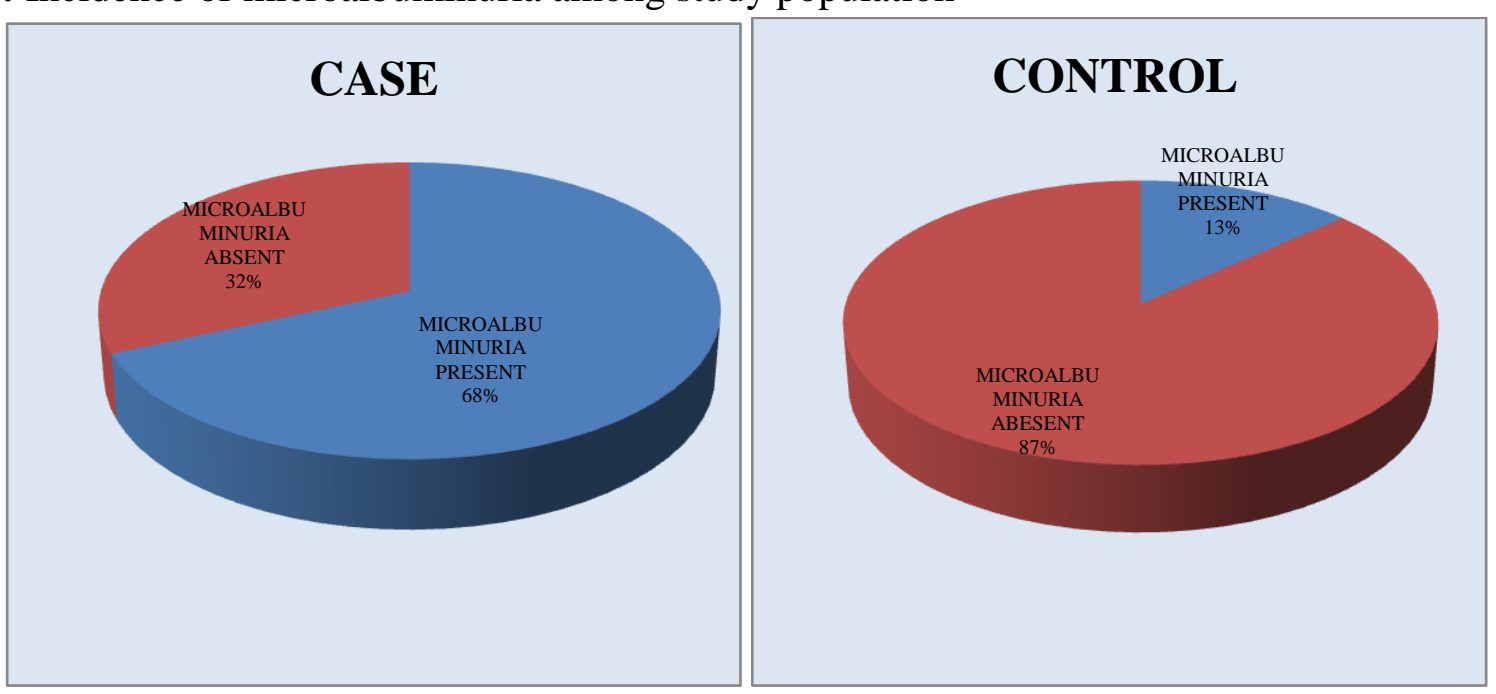




\section{JMSCR Vol||05||Issue||01||Page 15680-15715||January}

Microalbuminuria was found in $41(68.33 \%)$ patients with acute ischemic stroke while only 8 $(13.33 \%)$ controls. Thus patients with acute ischemic stroke were 5.125 times more like to have microalbuminuria when compared to the controls.

Table -5: Association of age / sex with the presence of microalbuminuria

\begin{tabular}{|l|c|c|c|}
\hline \multirow{2}{*}{} & \multicolumn{2}{|c|}{ Microalbuminuria } & p value \\
\cline { 2 - 3 } & Absent & Present & 0.066 \\
\hline $\begin{array}{l}\text { Age in years } \\
\text { Mean } \pm \text { SD) }\end{array}$ & $56.70 \pm 14.45$ & $63.18 \pm 11.66$ & $>0.05$ \\
\hline Sex & \multicolumn{2}{|c|}{$\begin{array}{c}\text { Male=13(65\%) } \\
\text { Female }=7(35 \%)\end{array}$} & $\begin{array}{c}\text { Male }=32(80 \%) \\
\text { Female }=8(20 \%)\end{array}$ \\
\hline Inference & $\begin{array}{l}\text { Age and sex are not statistically associated with the presence of } \\
\text { microalbuminuria }(\mathrm{p}>0.05) .\end{array}$
\end{tabular}

Figure-5: Association of age with the presence of microalbuminuria

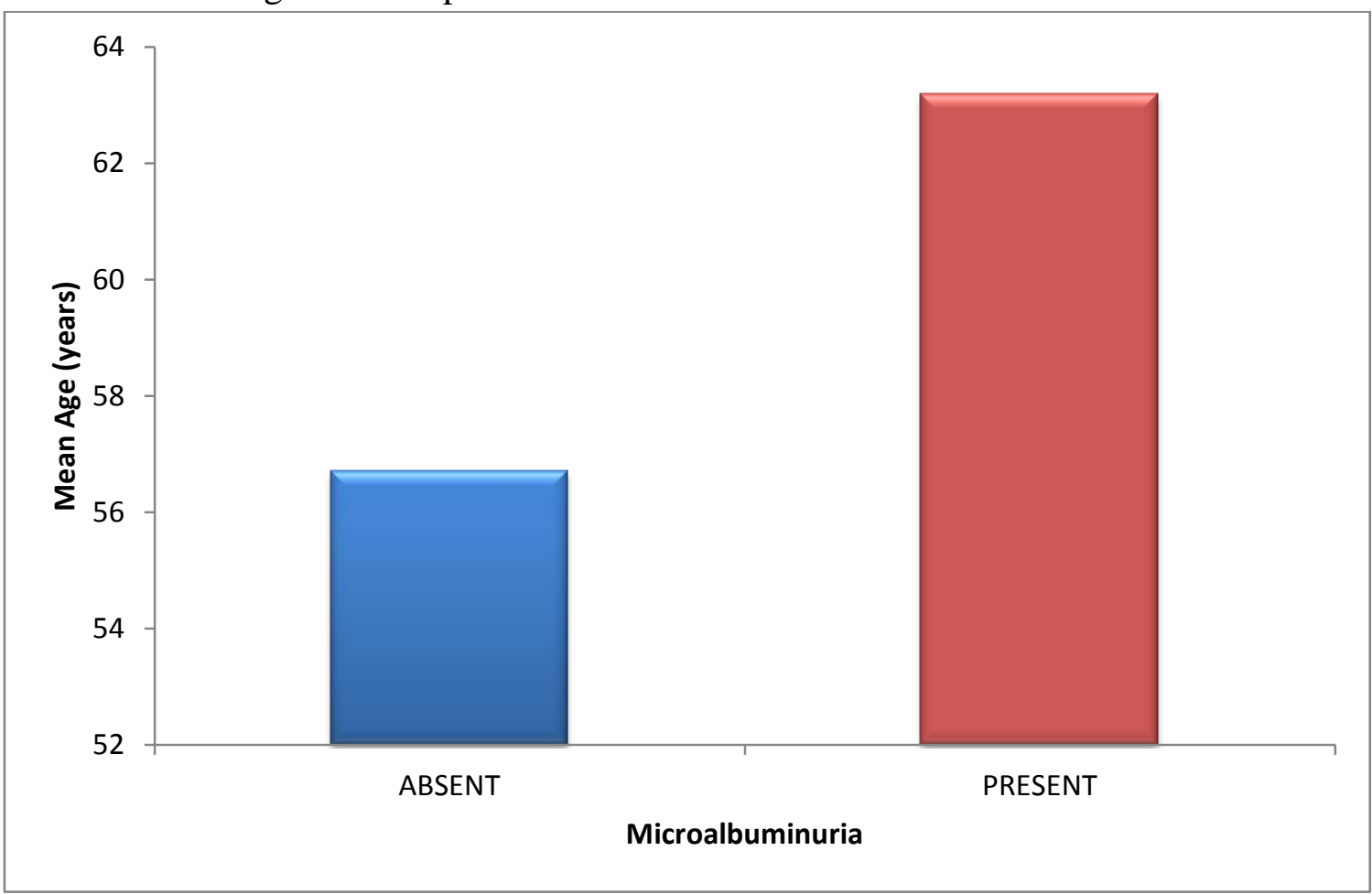

Figure-6: Association of sex with the presence of microalbuminuria

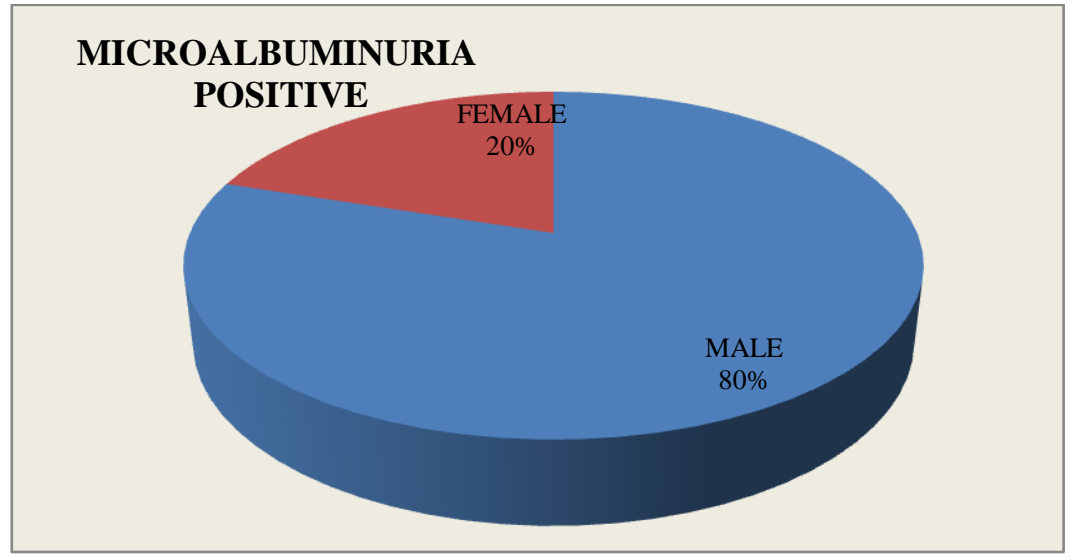




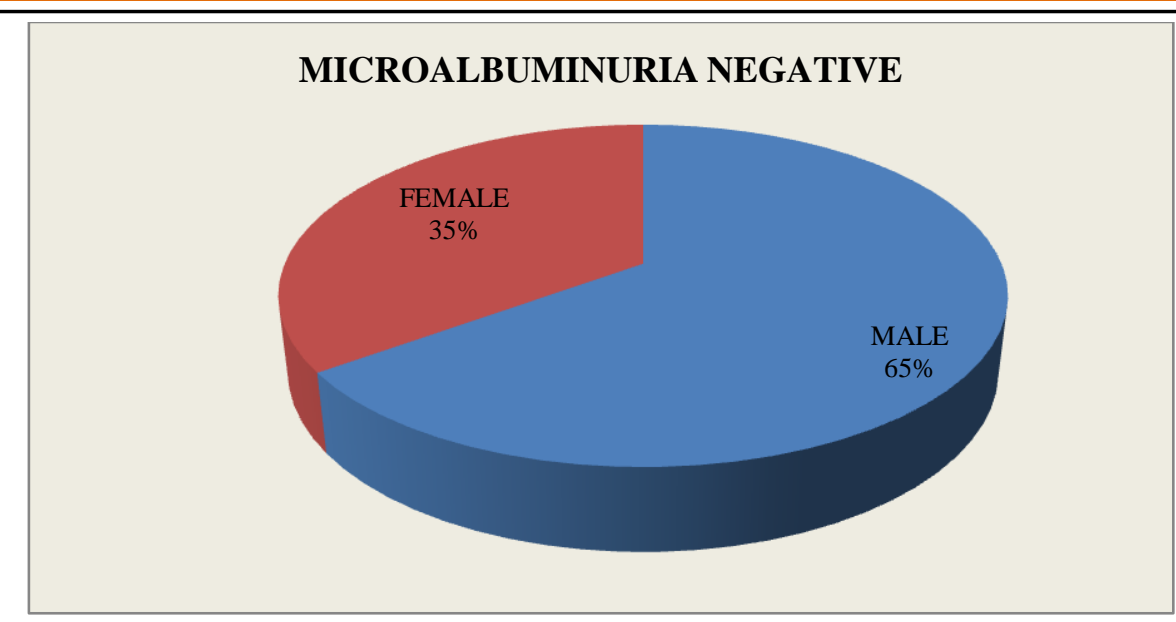

Of the 40 patients with microalbuminuria, 31 patients were above the age of 50 years but age was not statistically associated with presence of microalbuminuria(63.18 \pm 11.66 Vs. $56.70 \pm 14.45$ ).
Among the patients with microalbuminuria 32 were male and 8 female. gender was not statistically associated with presence of microalbuminuria.

Table -6: Mean pattern of parameters

\begin{tabular}{|l|c|c|c|}
\hline $\begin{array}{l}\text { Parameters } \\
(\text { Mean } \pm \text { SD) }\end{array}$ & Cases $(\mathbf{n = 6 0 )}$ & Controls $(\mathbf{n}=60)$ & P value \\
\hline SBP mm Hg & $125.10 \pm 10.84$ & $127.43 \pm 15.75$ & 0.3471 \\
\hline DBP mm Hg & $77.93 \pm 6.71$ & $76.67 \pm 5.58$ & 0.2657 \\
\hline RBS in g/dl & $107.11 \pm 20.51$ & $93.76 \pm 22.72$ & 0.0010 \\
\hline Blood urea in mg/dl & $43.99 \pm 16.04$ & $38.85 \pm 15.08$ & 0.0731 \\
\hline Serum Creatinine in $\mathrm{mg} / \mathrm{dl}$ & $1.06 \pm 0.36$ & $1.01 \pm 0.35$ & 0.4420 \\
\hline
\end{tabular}

Figure-7: Mean pattern of SBP \& DBP

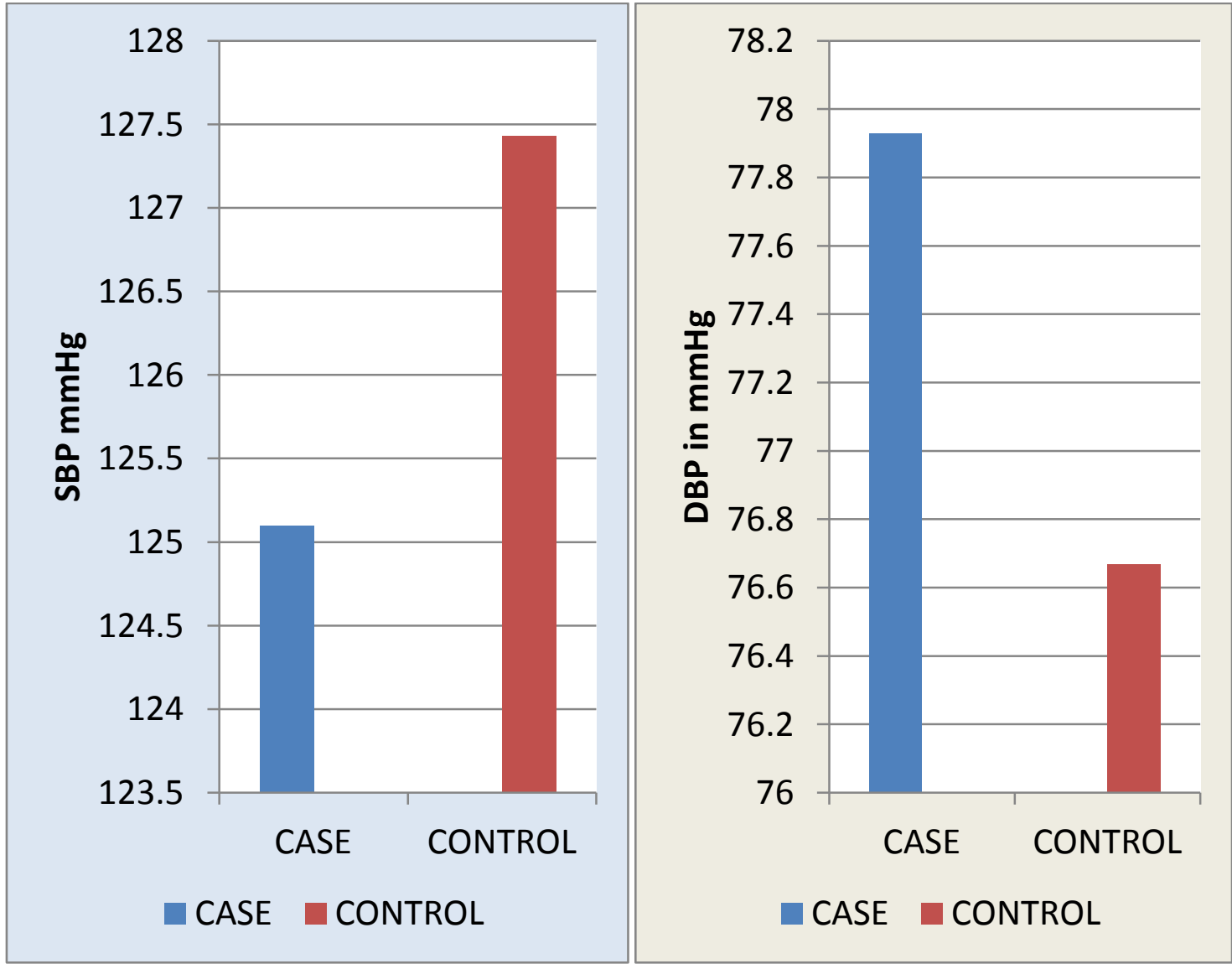


Figure-8: Mean pattern of RBS

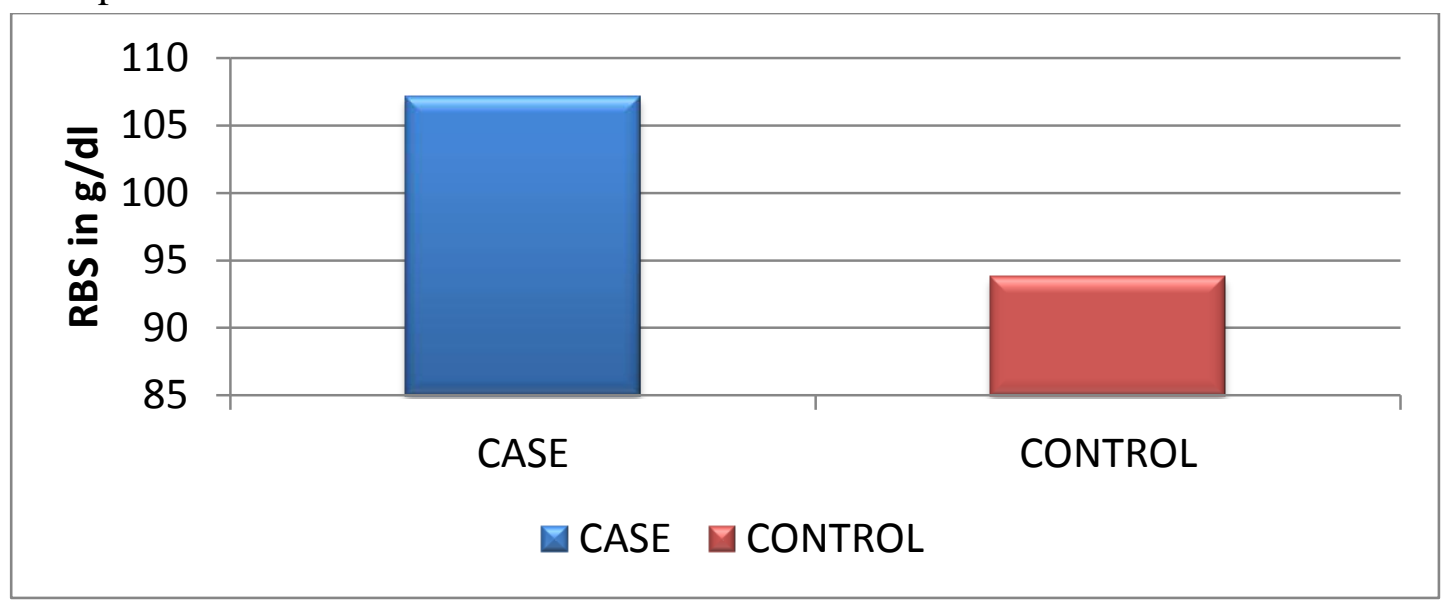

Figure-9: Mean pattern of S.Urea \& S. Creatinine

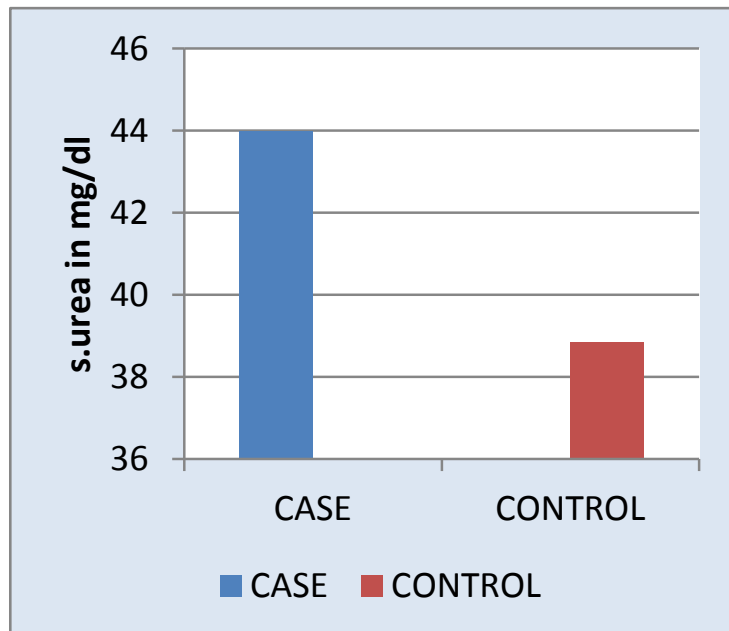

Blood pressure was found to be similar between cases and controls.

Blood Sugar was $107.11 \pm 20.51$ among cases while $93.76 \pm 22.72$ among controls and was statistically significant.

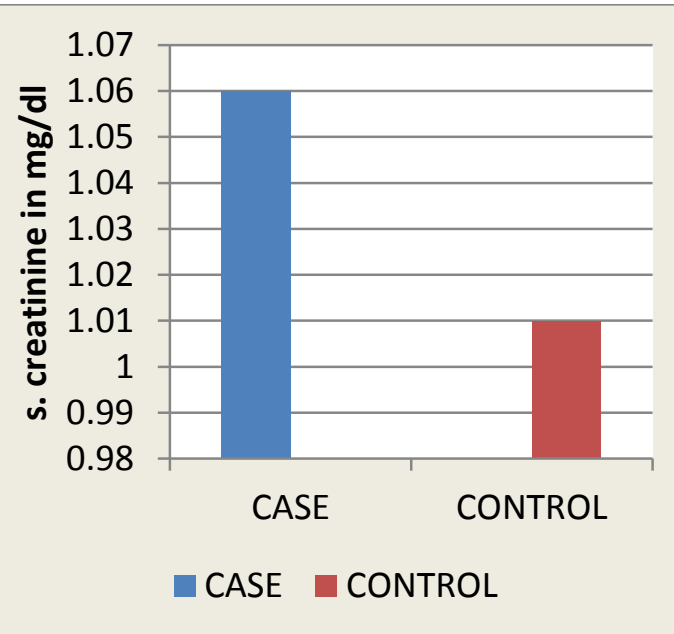

Among cases, blood urea was $43.99 \pm 16.04$, serum creatinine was $1.06 \pm 0.36$ while in controls, it was $38.85 \pm 15.08$ and $1.01 \pm 0.35$ respectively.

Table-7: Mean pattern of lipid parameters in cases

\begin{tabular}{|l|c|c|c|}
\hline \multirow{2}{*}{$\begin{array}{l}\text { Lipid Parameters } \\
\text { Mean } \pm \text { SD) }\end{array}$} & $\begin{array}{c}|c| \\
\text { Absent } \\
(\mathbf{n = 2 0})\end{array}$ & $\begin{array}{c}\text { M value } \\
(\mathbf{n}=\mathbf{4 0})\end{array}$ & \\
\hline Total Cholesterol & $140.23 \pm 37.65$ & $147 \pm 42.64$ & 0.5443 \\
\hline HDL-Cholesterol & $46.96 \pm 10.19$ & $49.59 \pm 10.25$ & 0.3518 \\
\hline LDL-Cholesterol & $77.46 \pm 33.92$ & $84.79 \pm 35.38$ & 0.4464 \\
\hline Triglycerides & $97.83 \pm 28.26$ & $121.89 \pm 46.88$ & 0.0395 \\
\hline
\end{tabular}


Figure- 10: Mean pattern of lipid parameters in cases

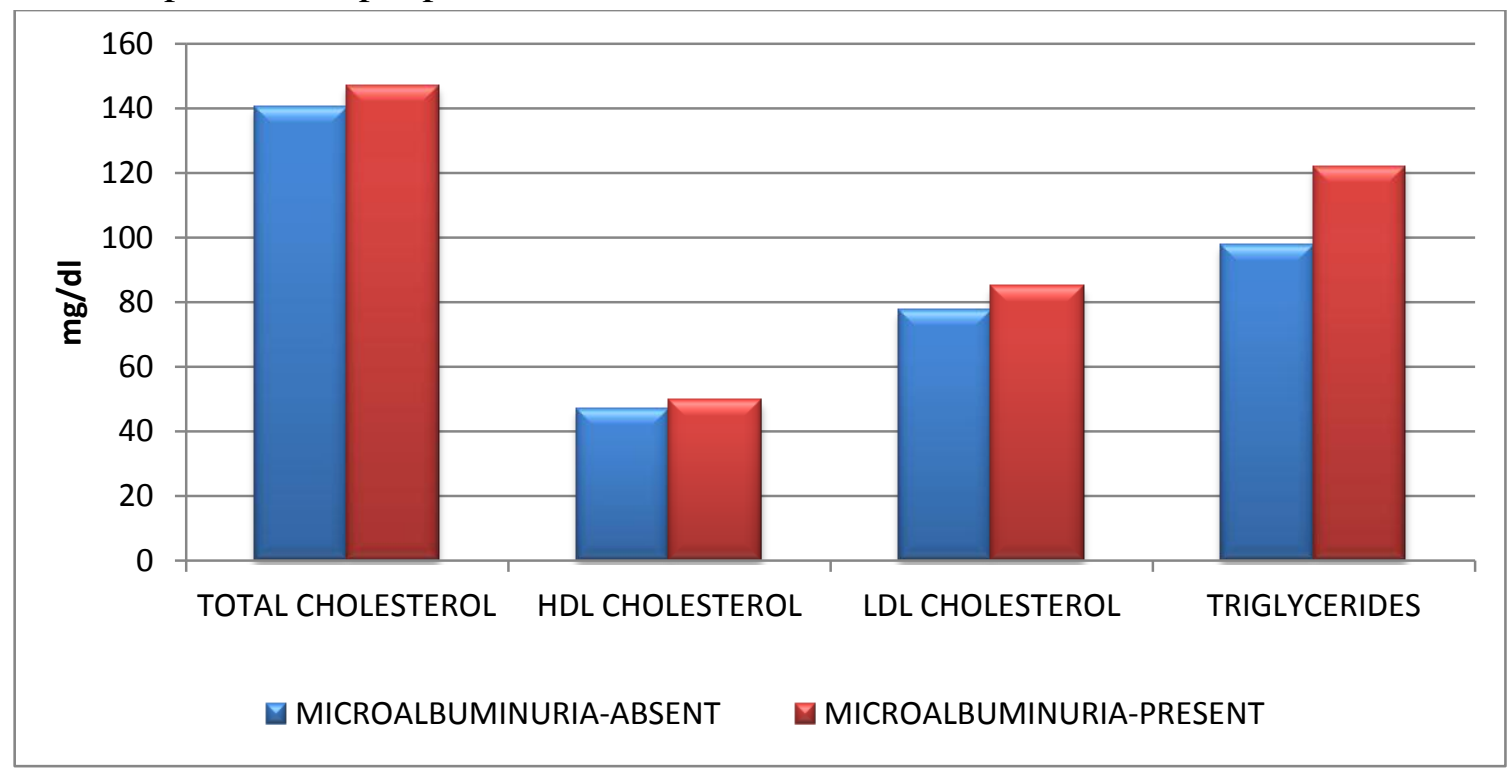

Total cholesterol $(147 \pm 42.64$ Vs. $140.23 \pm 37.65)$, was higher in patients with microalbuminuria but LDL cholesterol $(84.79 \pm 35.38$ Vs $77.46 \pm 33.92)$ the difference was found to be statistically and Triglycerides(121.89 \pm 46.88 Vs $97.83 \pm 28.26)$ significant only in case of Triglycerides.

Table -8: CT scan results

\begin{tabular}{|l|c|c|}
\hline CT scan results & $\begin{array}{c}\text { Number } \\
(\mathbf{n = 6 0 )}\end{array}$ & $\mathbf{\%}$ \\
\hline 1.Right ACA infarct & - & - \\
\hline 2.Left ACA infarct & - & - \\
\hline 3.Right MCA infarct & 30 & 50 \\
\hline 4.Left MCA infarct & 17 & 28.33 \\
\hline 5.Right PCA infarct & 2 & 3.33 \\
\hline 6.Left PCA infarct & 1 & 1.6 \\
\hline 7.Combined Lesion & 10 & 16.67 \\
\hline
\end{tabular}

Figure -11: CT scan results

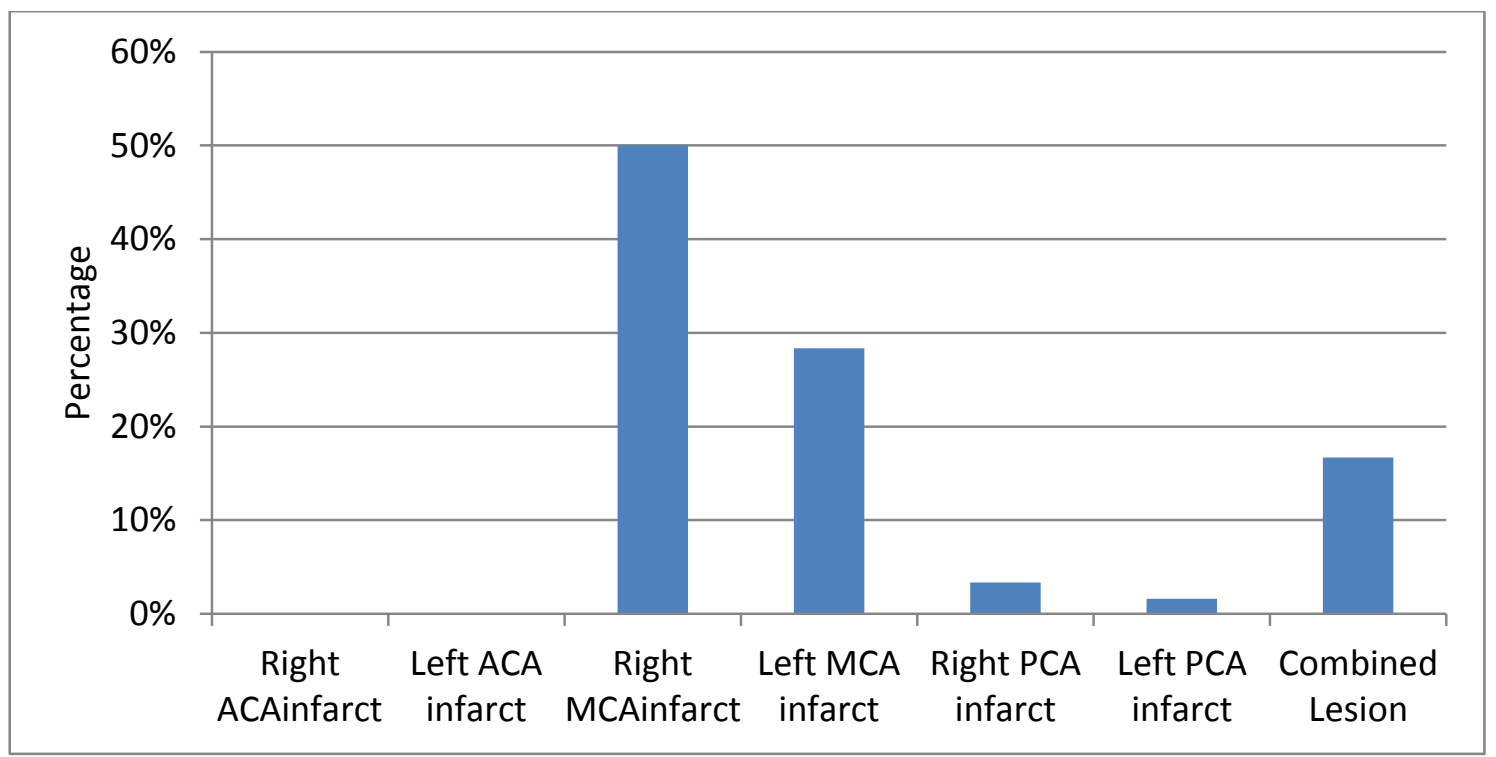

MCA infarct was the commonest lesion found in our study population (Rt $50 \%$ Vs Lt $28.33 \%$ ). Combined lesion was found in $(16.67 \%)$ patients.
Right PCA infarct was found in $(3.33 \%)$ patients and left PCA infarct was found in $(1.6 \%)$ patients. 
Table -9: Mean Pattern of Scandinavian Stroke Scale(SSS) in presence of Microalbuminuria

\begin{tabular}{|l|c|c|c|}
\hline $\begin{array}{l}\text { Scandinavian } \\
\text { Stroke Scale } \\
\text { (SSS) }\end{array}$ & $\begin{array}{c}\text { Absent } \\
(\mathbf{n}=\mathbf{2 0})\end{array}$ & $\begin{array}{c}\text { Present } \\
(\mathbf{n}=\mathbf{4 0})\end{array}$ & \multirow{2}{*}{$\begin{array}{c}\text { Total } \\
(\mathbf{n}=\mathbf{6 0})\end{array}$} \\
\cline { 2 - 4 } & $31-49$ & $4-48$ & $4-49$ \\
\hline Range & $40.4 \pm 5.09$ & $16.85 \pm 10.87$ & $24.7 \pm 15.17$ \\
\hline Mean \pm SD & \multicolumn{2}{|c|}{ SSS is significantly decreased in the presence of Microalbuminuria with $p<0.0001$} \\
\hline Inference & \multicolumn{3}{|c|}{} \\
\hline
\end{tabular}

Figure -12: Mean Pattern of SSS in presence of Microalbuminuria

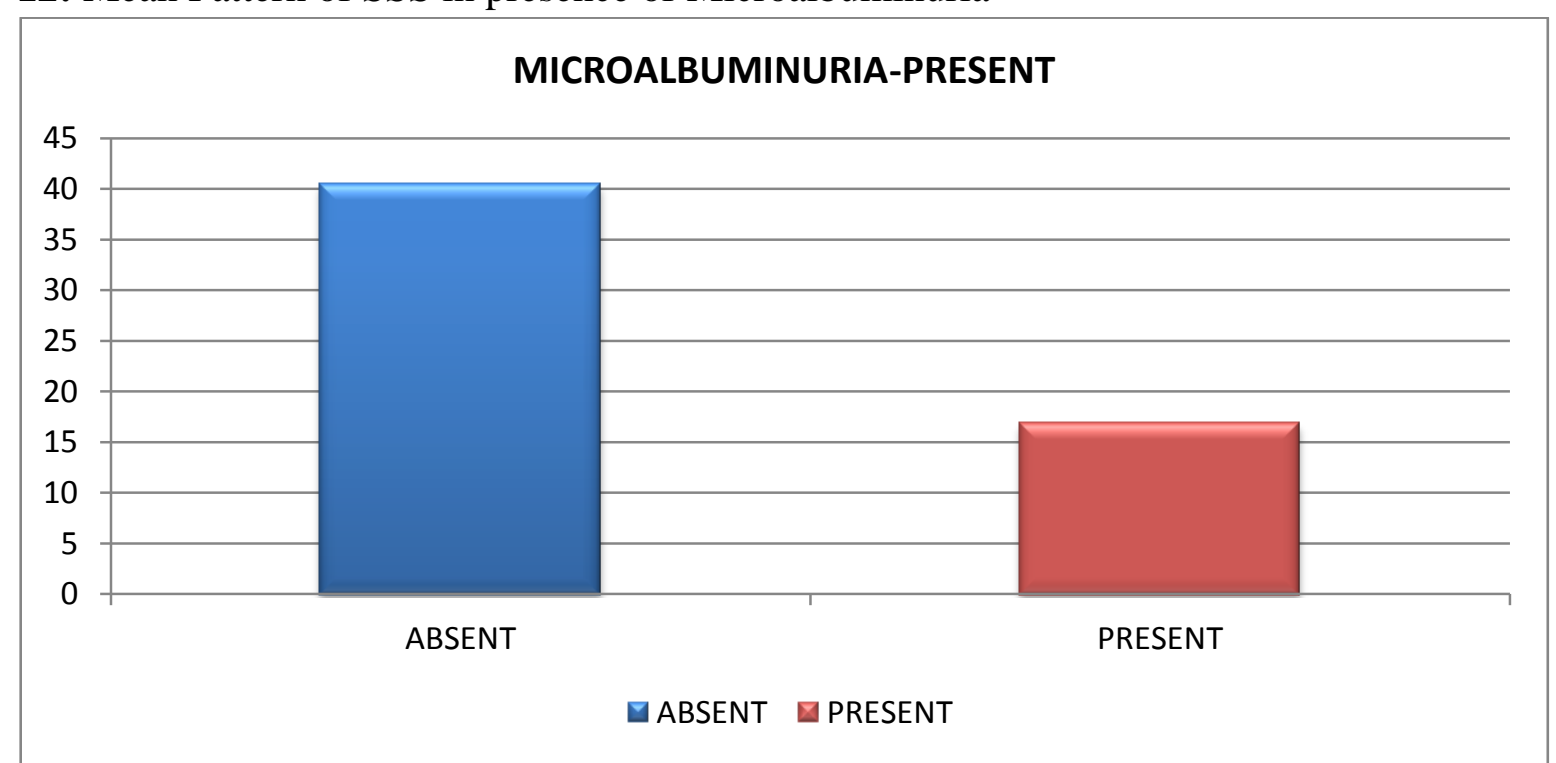

The severity of stroke was assessed by nuria (4-48 with mean of $16.85 \pm 10.87$ ) than Scandinavian Stroke Scale and was found to without microalbuminuria (31-49 with mean of significantly lower in presence of microalbumi40.4 \pm 5.09 ).

Table-10: Correlation of Level of Consciousness by SSS and MA

\begin{tabular}{|l|c|c|}
\hline Level of consciousness & $\begin{array}{c}\text { Number of patients without } \\
\text { microalbuminuria (MA) }\end{array}$ & $\begin{array}{c}\text { Number of patients with } \\
\text { microalbuminuria(MA) }\end{array}$ \\
\hline 2 & 2 & 24 \\
\hline 4 & 3 & 8 \\
\hline 6 & 15 & 8 \\
\hline
\end{tabular}

Fig. 13 Correlation of Level of Consciousness by SSS and MA

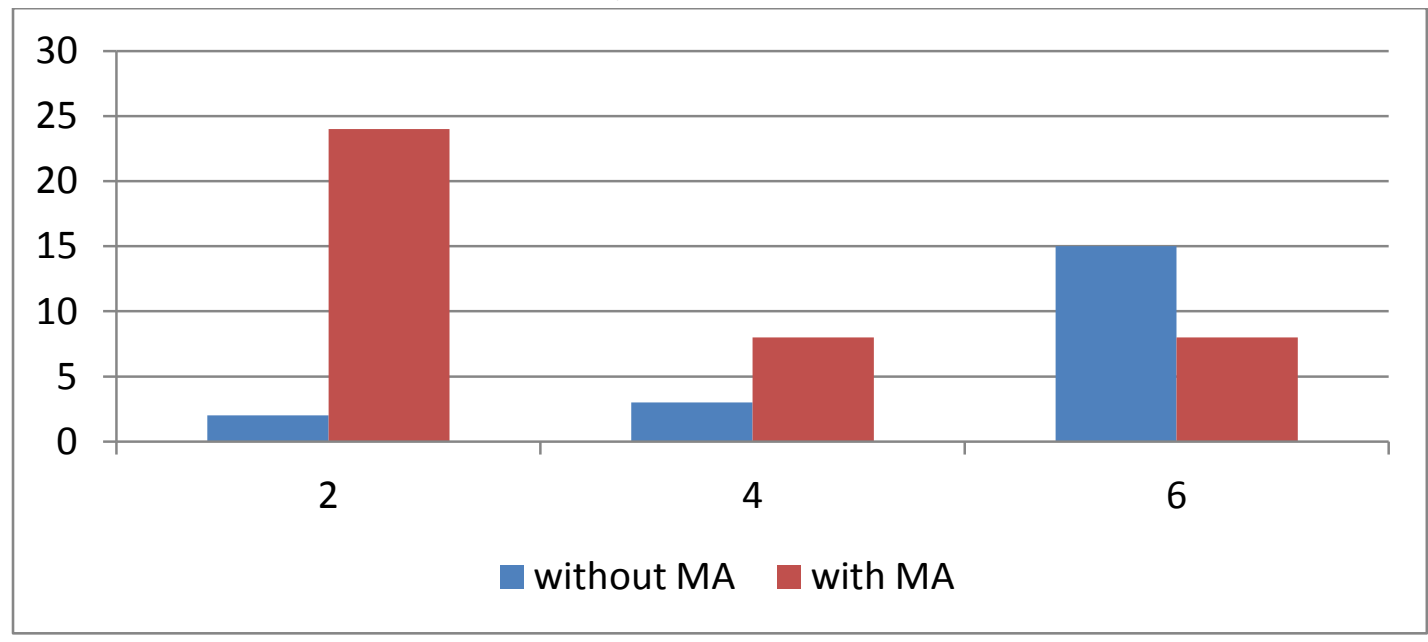

The Patients with MA had more severe depressed levels of consciousness, $60 \%$ of patients with MA had level of consciousness 2, whereas $10 \%$ of patients without MA had level of consciousness 2. 
Table-11: Scandinavian Stroke Scale (SSS) with increasing level of Microalbuminuria

\begin{tabular}{|l|c|}
\hline Microalbuminuria (mg/l) & Scandinavian Stroke Scale. (Mean) \\
\hline $20-60$ & $21.42 \pm 13.06$ \\
\hline $60-100$ & $15.2 \pm 7.01$ \\
\hline $100-140$ & $15.83 \pm 9.84$ \\
\hline $140-180$ & $12.0 \pm 5.66$ \\
\hline$>180$ & $12.66 \pm 10.48$ \\
\hline
\end{tabular}

Figure-14: Scandinavian Stroke Scale (SSS) with increasing level of Microalbuminuria

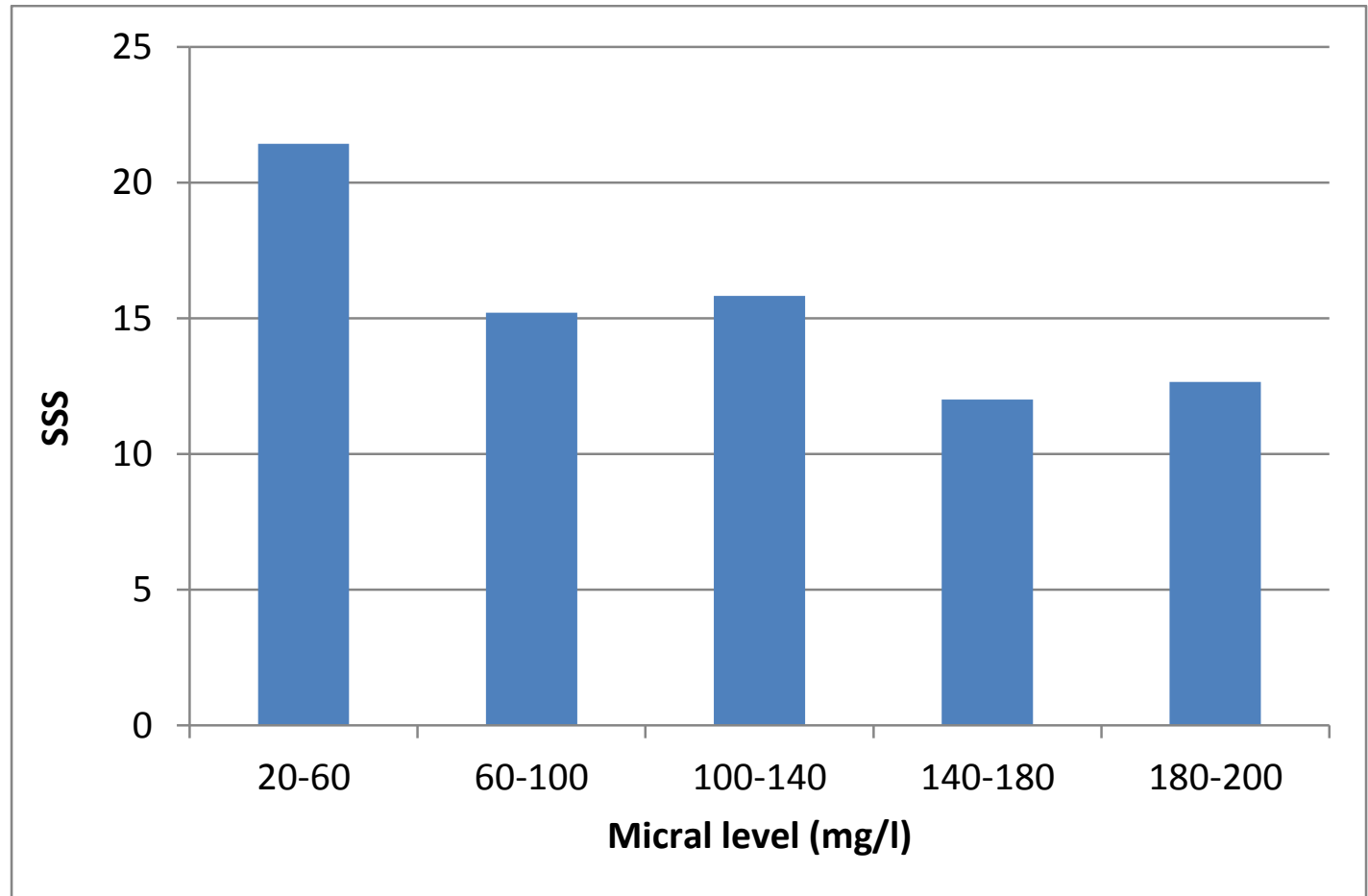

With increasing level of MA, the Scandinavian Stroke Scale (SSS) score decreases indicating poor prognosis with increase in MA level.

1. The incidence of microalbuminuria in Acute ischemic stroke patients.

2. The difference in laboratory parameters in patients with and without microalbuminuria.

\section{Discussion}

The present study is a comparative study consisting of 60 Acute ischemic stroke patients as cases and 60 Healthy individual as controls undertaken to investigate:

3. The correlation between Scandinavian Stroke Scale and presence of microalbuminuria.

\section{Incidence of microalbuminuria}

\begin{tabular}{|l|c|c|}
\hline & MA in cases & MA in controls \\
\hline Turaj et al & $46.1 \%$ & $13.5 \%$ \\
\hline Beamer et al & $29 \%$ & $10 \%$ \\
\hline Slowik A et al & $46.7 \%$ & $16.7 \%$ \\
\hline Present study & $68.33 \%$ & $13.33 \%$ \\
\hline
\end{tabular}

Our study found that among age and sex matched cases and controls with similar predisposing factors, patients with acute ischemic stroke were 5.125 times more likely to have microalbuminuria. The finding was similar to that of other studies including Turaj et $\mathrm{al}^{74}$, Beamer et $\mathrm{al}^{71}$ and Slowik A et al. ${ }^{82}$ 
The incidence of microalbuminuria in cases found

western population. greater in Indian population as compared to

\section{Age and microalbuminuria}

\begin{tabular}{|l|c|c|c|}
\hline & With MA & Without MA & Controls \\
\hline Turaj et al & $73.3 \pm 11.6$ & $66.0 \pm 12.4$ & $65.2 \pm 5.5$ \\
\hline Beamer et al & $69 \pm 7$ & $65 \pm 8$ & $66 \pm 8$ \\
\hline Present study & $63.18 \pm 11.66$ & $56.70 \pm 14.45$ & $59.88 \pm 13.1$ \\
\hline
\end{tabular}

The studies including Turaj et $\mathrm{al}^{74}$ and Beamer et $\mathrm{al}^{71}$ had found statistically significant correlation and attributed this to the phenomenon of older patients having a worse

neurological deficit. Our study found correlation between age and presence of microalbuminuria but it didn't reach statistically significant level.

\section{Gender and Microalbuminuria}

\begin{tabular}{|c|c|c|}
\hline & With MA & Without MA \\
\hline \multicolumn{3}{|c|}{ Turaj et al } \\
\hline Males & $12(50 \%)$ & $14(50 \%)$ \\
\hline Females & $12(50 \%)$ & $14(50 \%)$ \\
\hline \multicolumn{3}{|c|}{ Present study } \\
\hline Males & $32(80 \%)$ & $13(77.3 \%)$ \\
\hline Females & $8(20 \%)$ & $7(22.7 \%)$ \\
\hline
\end{tabular}

The study did not reveal any difference in gender distribution between patients with or without microalbuminuria. This was consistent with study by Turaj et al. ${ }^{74}$

\section{Loss of consciousness and microalbuminuria}

\begin{tabular}{|l|c|c|c|}
\hline & With MA & Without MA & p value \\
\hline Turaj et al & $35.5 \%$ & $14.3 \%$ & $<0.05$ \\
\hline Present study & $60 \%$ & $10 \%$ & $<0.05$ \\
\hline
\end{tabular}

Our study found statistically significant correlation between diminished consciousness between patients with and without microalbuminuria. The study by Turaj et $\mathrm{al}^{74}$ also had similar findings. Hence, presence of microalbuminuria was found to correlate with the severity of stroke.

Gumbinger $\mathbf{C}$ et al study show that MA was frequently found in acute ischemic stroke patients. It was associated with severe neurological deficit upon admission. MA in the acute phase was shown to be an independent predictor of poor outcome ${ }^{87}$

Our study also found similar results The Scandinavian Stroke Scale was low in patient with microalbuminuria $(16.85 \pm 10.87)$ when compared to patients without microalbuminuria
(40.4 \pm 5.09$)$. Hence significant correlation was found between microalbuminuria and the severity of the neurological deficit. The Patients with MA had more severe depressed levels of consciousness \{SSS < 4 vs. SSS > 6, 80\% vs. $20 \%$ ). In patients with acute ischemic stroke, 41 pts $(68.33 \%)$ had microalbuminuria. Hence patients with acute ischemic stroke incidence is significantly higher.

Mathur P.C. et al studied 50 patients of nondiabetic acute ischaemic stroke within 24 hours of onset of symptoms for MA by dipstick urinalysis in 2005 in India .The incidence of MA was $68 \%$ (34 patients). Of all the traditional risk factors for stroke-age, male gender, hypertension, dyslipidaemia, smoking, obesity - only age of patients ( $>60$ years) showed a positive correlation 
with the presence of MA $(<0.05)$. Patients with MA had more severe neurological deficit (Scandinavian Stroke Scale $\{$ SSS $\}<30$ vs. > 30; mean $+\mathrm{S} . \mathrm{D}=24.3+8.66$ vs. $30.3+10.3, \mathrm{p}<0.03)$ and more severe depressed levels of consciousness \{SSS < 4 vs. SSS > 6, 82.35 vs. 17.6, p<0.05). The incidence of MA in Indians with nondiabetic acute ischaemic stroke is significantly higher than that of western populations. Patients with MA in the first 24 hours after the onset of stroke have more severe neurological deficit and depressed levels of consciousness than patients without $\mathrm{MA}^{84}$.

In our study incidence of MA is 68.33\%(41 patients), The Scandinavian Stroke Scale was low in patient with microalbuminuria $(16.85 \pm 10.87)$ when compared to patients without microalbuminuria $(40.4 \pm 5.09)$. Hence significant correlation was found between microalbuminuria and the severity of the neurological deficit. The Patients with MA had more severe depressed levels of consciousness \{SSS < 4 vs. SSS > 6, $80 \%$ vs. $20 \%$ ). Patients with MA in the first 24 hours after the onset of stroke have more severe neurological deficit and depressed levels of consciousness than patients without MA. Results are similar.

\section{Limitations of the Study}

1. To assess the incidence of Microalbuminuria with nondiabetic acute ischaemic stroke requires further studies with large sample size.

2. For long term prognosis in non-diabetic acute stroke patients required a longer follow up study.

\section{Summary}

1. The study population consisted of 60 acute ischemic stroke patients of age $60.77 \pm 13.02$ years with 47 males $(78.33 \%)$ and 13 females (21.67\%).

2. The controls included 60 age and sex matched individuals.
3. The cases and controls were matched for predisposing factors that included smoking and alcohol.

4. Among the cases, 18 (30\%) had right hemiparesis, $32(53.3 \%)$ had left hemi paresis while $10(16.67 \%)$ had no focal deficits.

5. CT scan results revealed that middle cerebral artery infarct predominated the study population (right and left 78.33\%).

6. The blood sugar levels were higher in cases (107.11 \pm 20.51$)$ compared to controls (93.76 \pm 22.72$)$ despite being in nondiabetic range and were statistically significant. Other parameters like blood pressure, blood urea and serum creatinine were similar among cases and controls.

7. In patients with Acute ischemic stroke, 41pts $(68.33 \%)$ had microalbuminuria while among controls only 8 patients $(13.33 \%)$ had microalbuminuria. Hence patients with recent ischemic stroke were 5.125 times more likely to have microalbuminuria with $\mathrm{p}=0.0001$.

8. $24 / 60$ patients with microalbuminuria (60\%) had altered consciousness while 2/20 patients without microalbuminuria $(10 \%)$ had altered consciousness. Hence microalbuminuria was found to be associated with more severe stroke.

9. The mean age of patients with microalbuminuria was $63.18 \pm 11.66$ years while that of patients without MA was $56.70 \pm 14.45$ years. Hence presence of microalbuminuria was found to increase with age but not to the statistically significant level.

10. In patients with microalbuminuria, total cholesterol was $147 \pm 42.64$, HDL was $49.59 \pm 10.25$, LDL was $84.79 \pm 35.38$ and $121.89 \pm 46.88$ triglycerides while in patients without microalbuminuria, total cholesterol was $140.23 \pm 37.65$, HDL 46.96 \pm 10.19 , LDL $77.46 \pm 33.92$ and $97.83 \pm 28.26$ triglycerides. The difference 
was not statistically significant except in case of triglycerides.

11. The Scandinavian Stroke Scale was low in patients with microalbuminuria $(16.85 \pm 10.87)$ when compared to patients without microalbuminuria (40.4 \pm 5.09$)$. Hence significant correlation was found between microalbuminuria and the severity of the neurological deficit.

12. The Patients with MA had more severe depressed levels of consciousness \{SSS < 4 vs. SSS > 6, $80 \%$ vs. $20 \%$ ).

13. In patients with acute ischemic stroke, 41 pts $(68.33 \%)$ had microalbuminuria. Hence patients with acute ischemic stroke incidence is significantly higher than that of western populations.

\section{Conclusion}

- Various clinical studies have documented microalbuminuria as a risk factor for acute ischemic stroke. The present study found microalbuminuria in $68.33 \%$ of nondiabetic acute ischemic stroke patients.

- The incidence of MA in Indians with nondiabetic acute ischaemic stroke is significantly higher than that of western populations.

- Patients with MA in the first 24 hours after the onset of stroke have more severe neurological deficit and depressed levels of consciousness than patients without MA.

\section{Bibliography}

1. Goldstein L. Evidence - based medicine and stroke Neuroepidemiology 1999; 18; 120-124.

2. Hankey GJ. Stroke: how large a public health problem and how can the neurologist help? Arch Neurol 1999; 56: 748 754.

3. Ross R. Atherosclerosis: an inflammatory disease. N Engl J Med 1999; 340: 115-126
4. Kullo IJ, Gau GJ, Tajik AJ. Novel risk factors for atherosclerosis. Mayo Clin Pros 2000; 75: 369-380.

5. Hatano S. Experience from a multicentre Stroke register: A Preliminary Report, Bulletin WHO 1976; 54: 541-43.

6. Hankey GJ. Warlow CP. Transient ischemic attacks of the brain and eye. London; WB Saunders. 1994.

7. Srinivasan AV, Balasubramnian, N. Mahesh. An Overview of Stroke - Recent perspectives, Medicine update - APICON 2002. Editor SB Gupta 878-82.

8. Hachinski V, Norris IW. The Acute Stroke. FA Davis Company, 1985.

9. Park. K. Parks Textbook of Preventive and Social Medicine, 14th Edition Jabalpur. Banarsidas - Bhanot Publishers; 1994.

10. Devis HD et al. Epidemiology of Cerebrovascular Disease. In Anderson D ed. Neuroepidemiology A tribute to Bruce Schoenberg Boca Raton: CRC Press 1991; 27-53.

11. Kameshwar Prasad. Epidemiology of Cerebrovascular Disease in India. Recent concepts in stroke. Editor B.C. Bansal : 21-27.

12. Banford $\mathrm{J}$ et al. A prospective study of acute cerebravascular disease in the community: The Oxfordshire Community Stroke Project 1981-86: Methodology, demography and incident cases of first ever stroke. J Neurosurg Psych 1998; 51:1373 - 80 .

13. Rodgers A. et. al. Blood Pressure and the risk of stroke in patients with cerebrovascular disease . BMJ 1996; 313:147.

14. Sagie A et al. The natural history of borderline isolated systolic hypertension. N Engl J Med 1993; 329: 1612-1617.

15. Wolf PA et al. Probability of Stroke- a risk profile from the Framingham study Stroke $1991 ; 22: 312$. 
16. Shinton $\mathrm{R}$ et al. Meta analysis of relation between cigarette smoking and stroke. BMJ 1989; 298: 789-794.

17. Jurgens G. et al. LP (a) serum concentration and apolipoprotein (a) phenotype correlate with severity and presence of ischemic cerebrovascular disease. Stroke.1995; 26: 1841-48

18. Manson JE et al. A prospective study of maturity onset diabetes mellitus and risk of coronary heart diseases and stroke in women. Arch Intern Med 1991; 151:11411147.

19. Jorgensen $\mathrm{HS}$ et al. Intracranial haemorrhage versus infarction stroke severity, risk factors and prognosis. Ann Neurol 1995; 38: 45-50.

20. Qizilbash N. et al. Fibrinogen and lipids as risk factor of transient ischemic attacks and minor ischemic stroke. BMJ 1991; 303: 605-609.

21. Qizilbash N et al. Von Willebrand Factor and risk of ischemic stroke. Neurology 1997; 49: 1552-1556.

22. Welin L. et al. Analysis of risk factors for stroke in a cohort of men born in $1913 \mathrm{~N}$ Engl J Med 1987; 317: 521-526.

23. Yamanouchi $\mathrm{H}$ et al. Embolic brain infarction in non-rheumatic atrial fibrilation: A clinicopathologic study in the elderly. Neurology 1997; 48: 1593 - 1597.

24. Wannamethee S et al. Patterns of alcohol intake and risk of stroke in middle aged British Men Stroke 1996; 27: 1033 - 1039.

25. Kaplan NM. Alcohol and hypertension Lancet 1995; 345; 1588 - 1589.

26. Shinton R et al. Body fat and stroke. J Epidemiol Community Health 1995; 49: 259 - 264.

27. Ovencia AJ et al. Fish consumption and stroke in men. Stroke 1996; 27: 204-209.

28. Thelle DS. Salt and blood pressure revisited. BMJ 1996; 312: 1240-1241.
29. Whelton PK et al. Effects of oral potassium on blood pressure. JAMA 1997; 277: 1624-1632.

30. Lee IM et al. Exercise and risk of stroke in male physicians. Stroke 1999; 30: 1-6.

31. Kannel WB et al. Manifestations of CHD predisposing to stroke. JAMA 1983; 250: 2942 - 2946.

32. Craven TE et al. Evaluation of the association between carotid artery atherosclerosis and coronary artery stenosis. Circulation 1990; 82: 230-1242.

33. Natowicz $\mathrm{M}$ et al. Mendelian etiologies of stroke. Ann Neurol 1987; 22: 175-192.

34. Wade S. Smith, Claiborne Johnston, Donald Easton. Cerebrovascular Diseases, Harrisons Principles of Internal Medicine. 16th ed; Vol. II: 2372-2393.

35. Ralph L, Sacco, Danilo Toni, Mohr JP. Classification of ischaemic stroke. Stroke Pathophysiology, Diagnosis and Management. Editor - HIM Barnett, JP Mohr, BM Stun, FM Yatsu. 3rd ed, Churchill Livingstone 1998; PP 343.

36. Pushpa Yadav, BK Tripathi, AK Agarwal. Prognostication in stroke - Recent concepts in stroke. Editor: Bansal B. C., 301-310.

37. Multicenter trial of hemodilution is ischemic stroke - background and study protocol. Scandinavian Stroke Study Group. Stroke 1985; 16 (5): 885-90.

38. Loewen SC, Anderson BA. Predictors of stroke outcome using objective measurement scales. Stroke 1990; 21: 78-81.

39. Bangstad HJ, Try K, Dahl JK, Hansen KF. New Semiquantitative dipstick test for Microalbuminuria. Diabetes care 1991; 14: 1094-1097.

40. Andrew Hartland and Peter Gostling. Microalbuminuria: Yet another cardiovascular risk factor? Ann Clin Biochem 1999; 36: 700-703. 
41. Gosling P. Beevers DG. Urinary albumin excretion in the general population. Clin Sci 1989; 76: 39-42.

42. Stender S. Hjelms E. In vivo transfer of cholesterol from plasma into human aortic tissue. Scand J Clin Lab Invest 1987; 47: 21-29.

43. Lindberg G. Eklund GA. Gulberg B, Rastan G. Serum Sialic acid concentration and cardiovascular mortality. BMJ 1991; 302: 153-161.

44. Clausen P, Jensen J, Jenson $G$ et al. Elevated urinary albumin excretion is associated with impaired arterial dilatory capacity in clinically health subjects. Circulation 2001; 103: 1869 - 1874.

45. Lee $\mathrm{P}$, Jerkins A, Bourkhe $\mathrm{C}$ et al. Prothrombotic and antithrombotic factors are elevated in patients with type 1 diabetes complicated by microalbuminuria. Diabet Med 1993; 10 (2): 122-128.

46. Bhattacharya A. Microalbuminuria in diabetic nephropathy and as risk factor for cardiovascular disease. Chapter 66, Medicine update. Venkatraman S 2004; 14:405-409.

47. Kuusisto J, Mykkensen K, Pyorala K et al. Hyperinsulinemic microalbuminuria: A new risk indicator for coronary heart disease. Circular 1995; 91 (3): 831-837.

48. American Diabetes Association, Nephropathy in Diabetes (Position statement) Diabetes Care 2004; 27 (1): 79-83.

49. Rush University Hypertension Center. Microalbuminuria: What is it Why is it important? What should be done about it? J Clin Hypertens 2001; 3(2): 99-100.

50. Parving $\mathrm{HH}$ et al. Early detection of patients at risk of developing diabetic nephropathy; a longitudinal study of urinary albumin excretion. Acta Endocrinal (Copenti) 1982; 100: 550-555.

51. Viberti GC, Hill RD, Jarpet RJ et al. Microalbuminuria as a predictor of clinical nephropathy in Insulin Dependent
Diabetes Mellitus. Lancet 1982; 1: 1430 1432.

52. Mogensen CE. Microalbuminuria predicts clinical proteinuria and early mortality in maturity onset diabetes. NEJM 1984; 310: 356-60.

53. Allawi J, Jarrett RJ. Microalbuminuria and cardiovascular risk factors in Type 2 diabetes mellitus. Diabetes Med 1989; 7: 115-118.

54. Jorge L, Gross et al. Diabetic Nephropathy: Diagnosis Prevention and Treatment. Diabetes Care 2005; 28: 176188.

55. Consensus development conference on the diagnosis of coronary heart disease in people with Diabetes. Diabetes care 1998; 21: 1551-68.

56. Agarwal B et al. Microalbuminuria screening by reagent strip predicts cardiovascular risk in hypertension. J. Hypertension 1996; 14(2): 223-228.

57. Dansgaard EM et al. Microalbuminuria as predictor of increased mortality in elderly people. BMJ 1990; 300: 297-300.

58. Gosling P, Hughes EA, Reynolds TM, Fox JP. Microalbuminuria is an early response following acute myocardial infarction. Eur Heart J 1991; 12: 508-513.

59. Spyridon Koulouris et al. Microalbuminuria: A strong predictor of 3year adverse prognosis in non-diabetic patients with acute myocardial infarction. Am Heart J.

60. Roine I. Microalbuminuria: an index of severity in childhood meningitis. Pediatr Infect Dis J 1993; 12: 584-588.

61. Shearman CP, Gosling P, Walker KJ. Is low-level protein urea a predictor of severity in acute pancreatitis? J Clin Pathol 1989; 42: 1132-1135.

62. Pallister I, Gosling P, Alpar K, Gradley S. Prediction of post-traumatic adult respiratory distress syndrome by albumin 
excretion rate eight hours after admission.

J Trauma 1997; 42: 1056-61.

63. Pedersen LM et al Microalbuminuria in patients with rheumatoid arthritis. Ann Rheum Dis 1995; 54: 189-192.

64. Mahmood N. et al. Microalbuminuria: a disease activity marker of inflammatory bowel disease. Gut 1993; 34: 524.

65. Hickey NC et al. Effect of surgery on the systemic inflammatory response to intermittent claudication. Br J Surg 1009; 77: 1121-1126.

66. Mykkanen L et al. Microalbuminuria and carotid artery intima-media thickness in non-diabetic and NIDDM subjects. The Insulin Resistance Atherosclerosis Study (IRAS). Stroke 1997; 28: 1710 - 1716.

67. Else Marie Damsgaard et al. Microalbuminuria as predictor of increased mortality in elderly people. BMJ 1990; 300: 297300 .

68. John S. Yudkin et al. Microalbuminuria as predictor of vascular disease in nondiabetic subjects. Lancet 1988; 530-533.

69. Heikki Miettinen et al. Proteinuria predicts stroke and other atherosclerotic vascular disease events in non-diabetic and noninsulin dependent diabetic subjects. Stroke 1996; 27: 2033 - 2039.

70. Mlacak B. et al. Albuminuria, cardiovascular morbidity and mortality in diabetic and non-diabetic subjects in a rural general practice. Family Practice 1999; 16: 580-585.

71. Nancy B. Beamer et al. Microalbuminuria in ischemic stroke Arch Neurol 1999; 56: $699-702$.

72. Yuyun MF et al. Microalbuminuria and stroke in a British population: the European Prospective Investigation into cancer in Norfolk (EPIC-Norfolk) population study. J Intern Med 2004; 255(2): 247-256.

73. Hans L. Hillege et al. Microalbuminuria is common, also is a non-diabetic, non- hypertensive population and an independent indicator of cardiovascular risk factors and Cardiovascular morbidity, J Intern Med 2001; 249: 519-526.

74. Wojeiech Turaj et al. The prognostic significance of microalbuminuria in nondiabetic acute stroke patients. Med Sci Monit 2001; 7(5): 989-994.

75. Keen H, Chloverakis C. An immunoassay method for urinary albumin at low concentration. Lancet 1963; 2: 913-914.

76. Alfredo Pegoraro et al. Simplified screening for Microalbuminuria. Ann Intern Med 1997; 127: 817-819.

77. Magensen CE et al. Multicenter evaluation of the Micral-Test II test strip, an immunological rapid test for the detection of microalbuminuria. Diabetes cares 1997; 1642-1646.

78. Wachtell $\mathrm{K}$ et al. Albuminuria and cardiovascular risk in hypertensive patients with left ventricular hypertrophy. The LIFE STUDY. Ann Intern Med 2003; 139: 901-906.

79. UK Prospective Diabetes Study (UKPDS) Group intensive blood glucose control with Sulphonylureas or insulin compared with conventional treatment and risk of complications in patients with type 2 diabetes. Lancet 1998; 352: 837-853.

80. Smulders YM et al. Can reduction in hypertriglyceridemia slows progression of microalbuminuria in patients with NIDDM. Eur J Clin Invest 1997; 27 (12): 997-1002.

81. Radrigo Tagle, Monico Acevedo, Donald G. Vidt. Micro albuminuria: Is it a valid predictor of cardiovascular risk. Cleveland Clin J Med 2003; 70 (3): 255-261.

82. Slowik A et al. Microalbuminuria in nondiabetic patients with acute ischemic stroke: Prevalence, clinical correlates and prognostic significance. Cerebrovasc Dis 2002; 14 (1): 15-21. 
83. Beamer NB, Coull BM, Clark WM, et al, Microalbuminuria in ischaemic stroke, Arch Neurol. 1999;56:699-702.

84. Mathur PC, Punckar P, Murlidharan R, Microalbuminuria in Nondiabetic Acute Ischemic Stroke-An Indian Perspective, Ann Ind Acad Neurol 2005,Vol.8:237-242

85. Lima H.N., Cabral N.L., Gonçalves A.R.R., Association between Albuminuria, Glomerular Filtration Rate and Mortality or Recurrence in Stroke patients, Nephron Clin Pract 2011;117:c246-c252

86. Yoko Watanabe, Kae Ueda, Satoshi Suda, et al, Correlation between Proteinuria and the Condition of Patients with Acute Ischemic Stroke, J Nippon Med Sch 2011; 78 (6).

87. Gumbinger C, Sykora M, Diedler J, Ringleb P, Rocco A, Microalbuminuria: a potential prognostic marker for acute stroke,,Nervenarzt. 2012 Oct;83(10):135760.

88. Mathers, CD; Boerma, T; Ma Fat, D (2009). "Global and regional causes of death." British medical bulletin 92: 7-32. 
Annexure - 1: Proforma

PATIENT PROFILE:

NAME: OP/IP NO:

AGE: DOA: SEX: DOD: OCCUPATION: ADDRESS:

\section{PRESENTING COMPLAINTS:}

1. Paucity of movements of one side of the body

- Yes / No -

- Duration -

2. Loss of consciousness

- Yes / No-

- Duration -

3. Aphasia

- Yes / No -

- Duration -

4. Seizures

- Yes / No -

- Duration -

- Type -

5. Other Symptoms

\section{PAST HISTORY}

- HTN -

- Diabetes mellitus -

- Liver disorder -

- Renal insufficiency -

- History of vascular events -

\section{FAMILY HISTORY}

- HTN -

- Diabetes mellitus -

- Cerebrovascular accidents -

\section{PERSONAL HISTORY}

- Diet -

- Appetite -

- Sleep -

- Bowel movement -

- Bladder movement -

- Alcohol intake -

- Smoking -

\section{OBSTETRIC HISTORY}

(In Females)

\section{GENERAL PHYSICAL EXAMINATION}

- Built - Poor/ Moderate / Well

- Nourishment - Poor / Moderate / Well

- Pallor - 
- Icterus -

- Cyanosis -

- Clubbing -

- Lymphadenopathy -

- Oral cavity -

- Oedema -

- Weight -

- Height -

- Pulse -

- B.P. -

- Temperature -

- JVP -

$\cdot \mathrm{RR}-$

SYSTEMIC EXAMINATION

\section{CNS - Scandinavian Stroke Scale}

\begin{tabular}{|c|c|c|c|}
\hline Function & Score & $\begin{array}{l}\text { Prognostic } \\
\text { score }\end{array}$ & $\begin{array}{ll}\text { Long } & \text { term } \\
\text { score } & \\
\end{array}$ \\
\hline \multicolumn{4}{|l|}{ Consciousness: } \\
\hline - Fully conscious. & 6 & & \\
\hline - Somnolent can be awaked to full consciousness. & 4 & & \\
\hline - Reacts to verbal command, but not fully conscious. & 2 & & \\
\hline \multicolumn{4}{|l|}{ Eye movement } \\
\hline - No gaze palsy. & 4 & & \\
\hline - Gaze palsy present. & 2 & & \\
\hline - Conjugate eye deviation. & 0 & & \\
\hline \multicolumn{4}{|l|}{ Arm, motor power } \\
\hline - Raises arm with normal strength. & 6 & & \\
\hline - Raises arm with reduced strength. & 5 & & \\
\hline - Raises arm with flexion in elbow. & 4 & & \\
\hline - Can move, but not against gravity. & 2 & & \\
\hline - Paralysis. & 0 & & \\
\hline \multicolumn{4}{|l|}{ Leg, Motor power } \\
\hline - Normal strength. & 6 & & \\
\hline - Raises straight leg with reduced strength. & 5 & & \\
\hline - Raises leg with flexion of knee. & 4 & & \\
\hline - Can move, but not against gravity. & 2 & & \\
\hline - Paralysis. & 0 & & \\
\hline \multicolumn{4}{|l|}{ Orientation } \\
\hline - Correct for time, place and person. & 6 & & \\
\hline - Two of these. & 4 & & \\
\hline - One of these. & 2 & & \\
\hline - Completely disorientated. & 0 & & \\
\hline \multicolumn{4}{|l|}{ Speech } \\
\hline - No aphasia. & 10 & & \\
\hline - Limited vocabulary or incoherent speech. & 6 & & \\
\hline - More than yes / no, but not longer sentences. & 3 & & \\
\hline - Only yes/no or less. & 0 & & \\
\hline \multicolumn{4}{|l|}{ Facial palsy } \\
\hline - None/dubious. & 2 & & \\
\hline - Present. & 0 & & \\
\hline \multicolumn{4}{|l|}{ Gait } \\
\hline - Walks $5 \mathrm{M}$ without aids. & 12 & & \\
\hline - Walks with aids. & 9 & & \\
\hline - Walks with help of another person. & 6 & & \\
\hline
\end{tabular}




\begin{tabular}{|l|l|l|l|}
\hline$\cdot$ Sits without support. & 3 & & \\
\hline - Bedridden / wheel chair. & 0 & & \\
\hline Maximal Score & & & \\
\hline
\end{tabular}

2. Cardiovascular system

- Inspection -

- Palpation -

- Percussion -

- Auscultation -

3. Respiratory System

Inspection

Palpation

Percussion

Auscultation

INVESTIGATIONS

1. Urine Analysis

- Sugar

- Albumin

- Microscopy

2. Complete Haemogram

- $\mathrm{Hb} \%$ -

- TC -

- DC -

- ESR -

3. RBS

4. Blood Urea -

5. Serum Creatinine -

6. Fasting Lipid Profile

- TC -

- HDL -

- LDL -

- TG -

7. Chest X-ray PA view

8. 12 lead ECG

9. Echocardiogram

10. C.T Scan Brain

11. Micral test for Microalbuminuria 